
\title{
28 Research Suare \\ Experimental Study on the Law of Energy Dissipation and Damage in Coal Body Based on Local Tensile-Sliding Effect
}

\section{Xiangfeng LV}

School of Civil and Resource Engineering, University of Science and Technology Beijing

Xinyue Li ( $\square$ li-xy@xs.ustb.edu.cn )

University of Science and Technology Beijing https://orcid.org/0000-0003-1549-0666

\section{Yishan Pan}

School of Mechanics and Engineering, Liaoning Technical University;School of Physics, Liaoning University

\section{Research}

Keywords: Deformation localization, Intelligent image recognition Technology, Deformation displacement field, Strain energy ratio, Energy dissipation

Posted Date: May 13th, 2021

DOI: https://doi.org/10.21203/rs.3.rs-506260/v1

License: (c) (1) This work is licensed under a Creative Commons Attribution 4.0 International License. Read Full License 


\section{Abstract}

The slippage initiation and induced instability of roadway surrounding rock are highly likely to cause dynamic disasters, severely influencing the safety production of mining. With the optical-mechanical monitoring test of the deformation localization of energy dissipation, this study established the optical index of coal deformation equilibrium degree under load, and obtained the evolution law of coal deformation equilibrium degree. After analyzing the relationship between tensile-sliding effect and mechanical behavior of coal deformation field, it proposed the strain energy ratio coefficient. The results indicate that the strength reduction of coal body is affected by the deformation accumulation of loading displacement field. The sliding displacement of the stable sliding type specimen occurs $5.5 \mathrm{~s}$ earlier than tensile displacement $₫$ which is 4.4 s longer than the instantaneous instability type specimen. The instability type of coal is closely related to the tangent angle of the strain energy ratio coefficient and the damage persistence characteristics. The damage accumulation of stable equal amplitude contributes to the stable failure, and the damage accumulation of interval equal amplitude influences the instantaneous instability development. The fracture expansion stage is the main stage of energy consumption damage accumulation. That is, the main energy consumption damage accumulation stage of the stable slip coal is the stable crack expansion stage, with the damage proportion of $35.89 \%$, while the damage proportion of instantaneous instability coal in the unsteady crack expansion stage is $84.226 \%$. The study provides theoretical reference for the fracture law and risk monitoring of coal slippage.

\section{Introduction}

When the surrounding rock of the roadway starts to slip and becomes unstable, the energy released in the far field of the coal-rock system acts on the rock mass structure in the near field, damaging the supporting structure, deforming the mining space, and even causing casualties. As the statistics show, over $90 \%$ of dynamic disasters occur in the roadway. In China, underground mining is the mainstream of coal mining; every year, the length of newly-excavated roadway can reach 12,000 $\mathrm{km}$. During the past several years, coal rock dynamic disasters occurred in Tangshan Coal mine in Hebei province, Longgu Coal mine in Shandong province, and Mengcun Coal mine in Shaanxi province. These dynamic disasters caused huge economic loss and causalities. Accordingly, the prevention and control of dynamic disaster in coal-rock system has been a hot research issue (Fakhimi et al. 2016; Wu et al. 2020; Wang et al. 2020). Currently, many studies on dynamic slippage and instability of coal rock have been conducted, which lead to plentiful research results. Based on the combination of microseismic, electromagnetic radiation, mine pressure observation, drilling cuttings method and goaf gas analysis, Pan Yishan et.al put forward a multi-parameter comprehensive technology for rock burst prediction (Pan et al. 2018). Dou Linming et. al studied the principle of shock reduction via load reduction in fully mechanized caving of thick coal seam by means of field investigation, theoretical analysis, numerical simulation and engineering practice (Dou et al. 2020; Dou et al. 2020). They came to the conclusion that fully mechanized caving has a weakening effect on the stress concentration in stope and roadway surrounding rock. Kang Hongpu defined the damage caused by mining activities as the engineering problem in a four-dimensional space-time and 
thus concluded that the warning time of rock burst was one key parameter for the study on the occurrence, development and failure process of rock burst (Kang 2020). Up to now, most scholars place their academic focus on the stability control of coal and rock system after the occurrence of dynamic disasters in the working face. Their research achievement has solved most problems of dynamic disasters caused by slippage and instability (Tuncay et al. 2021; Jing et al. 2020; Maleki 2017). However, quite little has been done to study the disaster-causing mechanism of initiation precursor in the case that the energy released in the far field of the coal-rock system acts on the rock mass structure in the near field. Consequently, much remains unclear as for the initiation precursor of dynamic disasters. In this case, it is of great significance for coal mine safety production to study the initiation precursor of dynamic disasters so as to keep the roadway unblocked and stable.

Many scholars have employed various means to study the instability and failure characteristics of dynamic disasters in coal and rock systems. The relationship between deformation localization characteristics and coal rock stability has always been a hot and difficult issue in the field of rock mechanics. Scholars both at home and abroad have conducted much research work in this aspect. In terms of theoretical study, Yang Xiaobin et. al analyzed the evolution law of characteristic parameters under the influence of non-uniform deformation localization during cyclic loading and unloading by means of digital speckle correlation method (Yang et al. 2018; Yang et al. 2019). On this basis, they studied the mechanical response mechanism of rock material under cyclic loading and unloading. Peng Shoujian et. al studied the axial and radial strain field neograms of sandstone under triaxial stress conditions through a 3D-DIC testing system and analyzed the influence law of loading rate on the deformation localization of sandstone. They also explored the deformation localization characteristics of sandstone under different loading rates (Peng et. al. 2020). Zeng Yawu et. al analyzed the failure modes of rock materials under axisymmetric conditions based on discontinuous bifurcation theory and obtained the relationship between the azimuth angle of deformation localization band and confining pressure (Zeng et. al. 2020). Kang Qinrong et. al conducted a theoretical study on the formation and direction of localization of sandstone under the framework of equilibrium bifurcation theory and established the corresponding elastic-plastic constitutive model with nonlinear yield function and potential function (Kang et. al. 2020). In terms of experimental analysis, Xing Tongzhen et. al used digital image correlation method and acoustic emission technology to conduct uniaxial compression tests and analyzed the relationship between mechanical behavior and deformation evolution of specimens. Their study revealed the deformation mechanism of rock material (Xing et. al. 2020). Nunzio, Luciano, Fazio et. al studied the displacement field evolution of limestone samples in uniaxial compression tests by using the computer vision technology of non-contact digital image deformation detection, which proved that this technology can detect the displacement evolution before and after failure with high accuracy (Fazio et. al. 2019). Lei Ruide et. al used three-dimensional digital image correlation and acoustic emission technology to study the full-field strain and progressive cracking process. They also analyzed the deformation localization and damage characteristics of sandstone with two different geometrical defects under uniaxial compression (Lei et. al. 2020). Wang Gang et. al proposed a new method combining three-dimensional scanning technique and statistical analysis to reconstruct the evolution of pore size distribution during 
shearing (Wang et. al. 2021). On this basis, they put forward three models of particle deformation by conducting direct shear tests on artificial joints filled with particles of different sizes. In terms of numerical simulation, Li Yingjie et.al the artificial speckle field was employed in the digital speckle correlation method (DSCM) to monitor the evolution of the strain field on the surface of the plain strain model for tunneling during loading. A secondary strain-softening constitutive model using the numerical modeling code $\mathrm{FLAC}^{3 \mathrm{D}}$ was developed (degradation constitutive model) by considering the deformation mod-ulus degradation in the numerical simulation (Li et. al. 2014). Zhou Zilong et.al recorded and analyzed the deformation and failure process of specimens by digital speckle correlation method. The fracture form of the specimen was verified by $\mathrm{PFC}^{2 \mathrm{D}} \mathrm{s}$, and the relationship between the load state, strength and elastic modulus of the pillar and the bearing capacity of the pillar was obtained (Zhou et. al. 2017). By means of theoretical analysis, experimental research, and numerical simulation, scholars have made plenty of significant achievements in the following aspects: the formation mechanism of deformation localization, the parameters of deformation localization broadband and angle, and the evolution characteristics of deformation localization displacement. They also solved many engineering problems in this process (Li et. al. 2018; Sun et. al. 2019; Xie et. al. 2019; Yang et. al. 2018; Cao et. al. 2018). However, there are still some key issues that need to be further explored. One is the corresponding relationship between the evolution stages of coal rock localization and stability standards. To be specific, the evolution stages of coal rock localization would correspond to certain stability stages of coal rock. This can provide some theoretical reference for the critical model of coal and rock instability. Another key issue is the damage index of coal rock formed by deformation localization, in other words, how to characterize the relationship between coal rock damage and stability characteristics with certain monitoring index. This provides evaluation criteria for coal rock stability assessment.

In order to solve the problem of instantaneous dynamic instability of coal and rock mass and local information inversion, this study carried out an information identification experiment on intelligent image recognition and proposed the stability index of coal rock (M). On this basis, the evolution characteristics of different types of damages in brittle-hard coal were analyzed and the precursor information evaluation factors for dynamic instantaneous instability of coal rock were explored. Subsequently, the discriminative indexes of instantaneous instability of brittle-hard coal were obtained. This study provides reliable theoretical support and experimental basis for the monitoring of dynamic instantaneous instability precursors in the coal and rock mass in actual engineering fields.

\section{Localized Loading Test Of Coal Energy Dissipation Damage Deformation}

\subsection{Engineering structural model of pull-slip effect}

The use of narrow coal pillar in mining activities improves the recovery rate of coal resources. However, due to the weak bearing capacity and the development of structural cracks, the coal block slip instability occurs, and even threatens the safety of working face. As is shown in Figure 1, the model remains stable 
under the combined action of the applied stress from overlying strata and the bearing stress from the floor. As coal pillar is increasingly exposed and goaf enlarged, the bearing effect of coal pillars is gradually intensified. The collapse of liaison roadway, regional slip and dislocation, and even overall burst are in no way rare occurrence. In this paper, by analyzing the pull-slip effect of the coal at different stages of fracture in the same coal seam at the project site, with the aid of the light-force comprehensive test analysis method, the damage characteristics of the stable sliding and the instantaneous instability of the coal are studied, and the local tension-slip effect and the deformation evolution law of coal under load are analyzed, thus reveals the working face of coal damage macroscopic deformation and damage the internal relation of energy consumption.

\subsection{The test system for monitoring the mechanical property of deformation localization}

The data on localization can be obtained through the optical-mechanical test system. As is shown in Figure 2, this test system is composed of two subsystems: displacement-loading system and digital image recognition system. The displacement-loading system adopts RLJW-2000 hydraulic servo testing machine whose loading rate is $0.3 \mathrm{~mm} / \mathrm{min}$ to realize the loading of specimens and stress-strain data monitoring and collection during the whole process of loading. The digital image recognition system consists of two parts: hardware system and software system. The former includes CCD camera, light source, and computer. CCD camera can intelligently acquire the image pixel features of specimens during the loading process; white light source is used to irradiate the surface of samples to keep the grayscale of images unchanged; computer serves as the control center of the whole system to present, save, and process the images obtained during the test process and output the final results. The latter part, that is, the software system, is used to analyze and calculate the speckle imaged collected in the experiment so as to obtain the data on deformation fields such as displacement field, strain field and correlation coefficient distribution field of the specimens.

The experimental method can be stated briefly as follows: before the experiment, polish the surface of specimens to guarantee that the ends of the specimens are flat and smooth; then arrange artificial speckle field and install the monitoring systems; calibrate the displacement-loading system and digital speckle monitoring system to ensure that the data collection time of the whole test system should be strictly consistent during the experiment; the moment the experiment begins, trigger the loading device and digital speckle monitoring system to collect data throughout the whole loading process till the end of the experiment.

\subsection{Specimens and whole-process physical characteristic analysis}


The specimens were taken from complete coal produced in the mining area of Inner Mongolia autonomous region, China. The complete coal which was in a natural dry state was processed into specimens of $50 \mathrm{~mm} \star 50 \mathrm{~mm} \star 100 \mathrm{~mm}$. Black and white paint was sprayed over the surface of specimens to make artificial speckle field. Then the specimens were loaded at a loading rate of $0.3 \mathrm{~mm} / \mathrm{min}$ through displacement. With Basler A641f CCD camera, the image data revealed on the surface of specimens was acquired at a rate of $5 \mathrm{frame} / \mathrm{s}$. The image resolution ratio was $1600 \times 1200$ pixel and that of object plane was $0.1136 \mathrm{~mm} /$ pixel. Eight groups of experiments were conducted during the whole experimental process. According to experimental phenomenon and data feedback, 1 \# specimen and $2 \#$ specimen were extracted as the typical damage sample for the following analysis. Figure 3 shows the two specimens, their respective speckle images, and image analysis areas.

Given that this study aimed to explore the correlation between the stability of hard brittle coal under load and deformation localization, two specimens were selected out of the total eight groups of specimens as the representative experimental results according to the stress-strain curve during the whole loading process. The two selected specimens were marked as $1 \#$ and $2 \#$, respectively. $1 \#$ specimen is a case of stable slip and its stress-strain curve during the whole loading process is shown in Figure 4 (a); 2\# specimen represents a case of instantaneous instability and its stress-strain curve is shown in Figure 4 (b). As can be seen from the figure, Point A refers to the reference point for digital speckle correlation method; Point B-G correspond to the deformation images taken by the digital speckle correlation method.

As is shown in Figure 4 (a), the stress-strain curve of 1 \# specimen during the whole loading process can be clearly divided into five stages: compaction stage (I), elastic deformation stage (II), stable development and expansion stage (III), unstable expansion stage (IV), and post-peak failure stage (V). The main characteristic of compaction stage is that the original damage crack is compacted inside the specimen and there is virtually no crack expansion or fracture. As for the elastic deformation stage, it is featured with the continuous energy storage due to the external loading, which causes crack expansion partially; but the overall strength of specimen increases. The main characteristic of stable development and expansion stage is that after the crack initiation point, stress drop is rather clear; the elastic energy release occurs during this stage and the crack damage extends until the bearing capacity of specimen declines sharply. The unstable expansion stage is mainly featured with the rapid expansion of microcracks up to fracture penetration which deteriorates the damage. The main characteristic of post-peak failure stage is the occurrence of macro fracture zones, tremendous energy release, and stress decline. As Figure 4 (b) shows, the stress-strain curve of $2 \#$ specimen during the whole loading process is composed of four stages: compaction stage (I), elastic deformation stage (II), stable development and expansion stage (III), and unstable expansion stage (IV). The lack of post-peak failure stage can be justified by the fact that $2 \#$ specimen belongs to instantaneous instability. Before reaching the peak value, the specimen experienced two stages: the compaction stage during the early period of loading and the elastic deformation stage. After the peak value, the specimen experienced a short sub-instability stage and then instability failure with sudden stress drop occurred.

(1) 1\# specimen of stable slip (b) 2\# specimen of instantaneous instability. 
The failure modes and maximum shear strain diagram of the two specimens are shown in Figure 5. The failure modes of both specimens are featured with overall instability caused by main fissure penetration. However, in the case of $1 \#$ specimen, fissure penetration occurs only once; whereas in the case of $2 \#$ specimen, multiple associated cracks are formed at the early stage of main fissure penetration. Figure 5 (a) shows the failure mode and maximum shear strain diagram of 1 \# specimen. As can be seen, the width of deformation localization band is about $20 \mathrm{~mm}$; the maximum shear strain within the band is approximately $9.27 \times 10^{-3}$; the maximum shear strain outside the band is approximately $2.9 \times 10^{-3}, 31.3 \%$ of that within the band. Figure 5 (b) displays the failure mode and maximum shear strain diagram of $2 \#$ specimen. As can be seen, the width of deformation localization band is about $10 \mathrm{~mm}$; the maximum shear strain within the band is approximately $1.47 \times 10^{-3}$; the maximum shear strain outside the band is approximately $8.13 \times 10^{-4}, 55.3 \%$ of that within the band. Through comparing the deformation localization bands of the two specimens, it can be concluded that in the case of 2\# specimen (instantaneous instability type), the distribution of shear strain localization band presents a "zigzagging" distribution due to the associated crack expansion during the loading process; furthermore, the internal shear strain is smaller than that of $1 \#$ specimen (stable slip type). This can be justified essentially by the fact that the extension of local associated cracks leads to the deflection of the main crack penetration. From the quantitative point of view, under the same stress load, the specimen of instantaneous instability experiences less local deformation and damage, but the elastic energy accumulated inside the specimen is much higher, which is more suitable for instantaneous deformation.

\section{The Analysis Of Localized Deformation Law Of Coal Rock Under Load}

By means of intelligent image recognition technology and digital speckle correlation method, the deformation law of the specimens during the whole loading process was analyzed. To be specific, the process of deformation localization evolution of $1 \#$ specimen (stable slip type) and 2\# specimen (instantaneous instability type) was studied respectively to analyze the spatiotemporal characteristics and displacement evolution characteristics of different stages of deformation localization.

\subsection{The analysis of localized deformation during the whole loading process}

Damage and deformation occur to the coal rock under load. Due to the heterogeneity of rock structure, the damage of the specimen displays obvious localization characteristics during the loading process. Therefore, the data graphs of the specimen before the experiment, before cracking and after fissure penetration are extracted for image data recognition to capture the evolution law of damage and deformation of the coal rock.

The speckle calculation nephograms of two types of specimens (stable slip type and instantaneous instability type) during the loading process are shown in the following Figure 6 . The stress transfer law of 
rock in the early loading process can be described in detail by means of strain balance degree (Song et. al. 2012). To be specific, the strain balance degree of the specimen can be characterized by the ratio of transverse displacement to

axial displacement: . During the compaction stage of loading process, the balance degree of $1 \#$ specimen (stable slip type) evolves from disorder to order, as is shown in Figure 6 (a). The $5 s$ image collected by CCD camera is extracted and displayed in Figure 6 (a). It shows that the overall balance degree of the specimen is in a disordered state during the compaction stage. As can be seen from Figure 6 (a), the balance degree evolves from disorder (the $5 \mathrm{~s}$ image) to order (the $80 \mathrm{~s}$ image) as time goes by. The whole process takes $60 \mathrm{~s}$. Figure 6 (b) shows the shear strain nephogram within the period of $15 \mathrm{~s}$ from the moment of loading to main fracture penetration. As is shown, the specimen of stable slip type displays obvious characteristics of shear strain localization band during the early period of main fracture penetration. And the shear strain localization band evolves from "local divergence" to "local concentration, which is shown by the images numbered from $323.75 \mathrm{~s}$ to $338.75 \mathrm{~s}$. In other words, within the short period of main fracture penetration, a clear localization band can be formed at the end of penetrating fracture. This phenomenon provides a new monitoring direction for the precursor prediction of main fracture penetration in the rock mass. When the specimen enters the post-peak damage stage of loading, the main fracture penetrates the specimen and thus leads to an obvious shear strain reduction along the direction of main fracture. It is from this moment that the stress intensity begins to decline and enters the post-peak shear strain reduction stage.

As for the specimen of instantaneous instability type, it takes longer (315s) to adjust its degree of balance. Figure 7 (a) shows the nephogram of balance degree within the time period of $315 \mathrm{~s}$. As can be seen, during the compaction stage, the specimen also experiences the evolution of balance degree from disorder to order. Compared with the case of intact specimen, the shear strain localization band appears later (the 692.25s image), but lasts longer, which is shown in Figure 7 (b). The nephogram of shear strain localization band is more complicated due to the higher complexity of fissure distribution in the specimen. To be specific, there are several localized concentration areas inside the specimen, and strip continuous shear localization is formed especially at the position through which the main crack penetrates. As the main fracture penetrates the specimen and the overall strength reaches the peak, instantaneous instability occurs in the specimen. And accordingly there is no obvious post-peak characteristic.

As can be concluded from the above analysis, the strain balance of both specimens evolves from disorder to order during the loading process. As for 1 \# specimen, the time of balance degree adjustment is only $25.4 \%$ of that of $2 \#$ specimen. In the subsequent localized development process, the prefabricated time of $1 \#$ specimen is 243.75 s, while that of $2 \#$ specimen is $377.25 s$; the loading time of $1 \#$ specimen is $64.6 \%$ of that of $2 \#$ specimen. Therefore, in the early stage of the main crack formation, the overall work time of 2\# specimen is longer. Therefore, further research on the damage evolution of specimen should be conducted through displacement damage data. 


\subsection{The analysis of deformation localization characteristics in coal rock}

With the main penetration crack of the specimen as the reference interface, 6 groups of measuring points were arranged from bottom to top to capture the data of tensile and slip characteristics of the rock specimen in the loading process. The localization characteristics of coal and rock deformation were analyzed with the parameters like relative displacement quantity, displacement amplitude, tensile quantity and tensile amplitude. Figure 8 shows the displacement distribution of 1\# specimen (stable slip type) and $2 \#$ specimen (instantaneous instability type). The data on the relative displacement of $1 \#$ specimen is shown in Figure 8 (a). As the data indicates, the relative displacement increases slowly without obvious fluctuation before reaching the stress peak; when the stress reaches its peal value and main fracture penetration occurs, the relative displacement quantity displays a saltatory change at all measuring points. To be specific, at 2\#, 3\#, and $4 \#$ measuring point, the relative displacement shows a saltatory drop; at $1 \#, 5 \#$, and $6 \#$ measuring point, the relative displacement shows a saltatory increase; the maximum increase amplitude of relative displacement appears at $6 \#$ measuring point whereas the maximum drop amplitude appears at $3 \#$ measuring point. Figure 8 (b) shows the curve of relative displacement amplitude of $1 \#$ specimen. At the moment when the main crack penetrates the specimen under load, the slip characteristics of different regions of the specimen are different. That is, the upper part of the specimen is dominated by negative slip, while the lower part is dominated by positive slip, which leads to regional slip difference when the main crack penetrates the specimen. In this case, the directional development of cracks can be realized: from negative slip to positive slip, which makes the crack extend in a direction more conducive to the development of crack. Comparative analysis shows that the time of maximum sliding displacement of coal body is $331.1 \mathrm{~s}$, and the time of peak stress of coal body is $338.6 \mathrm{~s}$. Therefore, the time of sliding displacement of coal body is $7.5 \mathrm{~s}$ in advance of the peak stress point.

The data on the relative displacement of $2 \#$ specimen is shown in Figure 8 (c). As the data indicates, during the compaction stage, the relative displacement quantity of $2 \#$ specimen shows no obvious change compared with the data of $1 \#$ specimen. Due to the relatively developed micro-cracks in the specimen, a $2 \mathrm{~mm}$ slippage occurred before entering the elastic stage, and the obvious block spalling occurred during the loading process, which was the same as the local strain difference phenomenon in the localized analysis of the specimen. Thereafter, there was no obvious slip before reaching the peak value. Similar to the case of $1 \#$ specimen, positive slip and negative slip appear in $2 \#$ specimen. As is shown in Figure 8 (d), the maximum displacement amplitude of positive slip occurs at $6 \#$ measuring point, being $176 \%$. This indicates that before the maximum amplitude of negative slip appears at 5 \# measuring point, being $97.2 \%$. The maximum sliding displacement amplitude of coal mass is $710.7 \mathrm{~s}$, and the arrival time of the peak stress is $707.1 \mathrm{~s}$, so the sliding displacement time lags behind the peak stress point by $3.6 \mathrm{~s}$. In addition, the data analysis of displacement amplitude in 1 \# specimen and 2 \# specimen shows that the displacement process is clearly featured with staggered evolution. That is, at each measuring points, both positive slip and negative slip coexist, indicating that the extension of main crack 
is featured with staggered extension during the loading process. However, in different local areas in the specimen, certain directional slip still exists and serves as the main direction of main crack extension. By comparing the time characteristic of coal sliding under loading, it is shown that the sliding displacement of stable sliding coal occurs before the peak stress loading, while the sliding displacement of instantaneous instability specimen occurs after the peak stress loading.

The data on the relative tensile displacement of $1 \#$ specimen is shown in Figure 9 (a). As the data indicates, there is no saltatory increase or drop in the relative tensile displacement before reaching the stress peak; when the specimen enters the stable development and expansion stage, the tensile displacement increases slightly; when the stress reaches its peak value and the main penetration crack is formed, at 1\#, 5\#, and $6 \#$ measuring point, the relative tensile displacement shows a saltatory drop; at 2\#, $3 \#$, and $4 \#$ measuring point, the relative tensile displacement shows a saltatory increase; the maximum amplitude of negative tensile displacement $(10 \mathrm{~mm})$ appears at $1 \#$ measuring point whereas the maximum amplitude of positive tensile displacement $(2.4 \mathrm{~mm})$ appears at $2 \#$ measuring point. By contrast, the maximum tensile displacement at $2 \#$ measuring point appears earlier than that at $1 \#$ measuring point. To be specific, the tensile displacement at 1 \# measuring point increases as the load increases till the end of the experiment. From Figure 9 (b) it can be seen that during the early period of stress peak, staggered saltatory changes are observed and recorded at $3 \#$ and $6 \#$ measuring point. This indicates that in the early period of stress loading, tensile displacement occurs frequently in the areas of $3 \#$ and $6 \#$ measuring points. Accordingly, the amplitude of relative tensile displacement varies actively until the stress reaches its peak value and the main penetration crack is formed. At $4 \#$ measuring point, the tensile displacement witnesses a saltatory increase, and then a saltatory drop, indicating that the area of $4 \#$ measuring point is a sensitive area for tensile displacement monitoring. The time when the maximum tensile displacement of coal occurs is $336.6 s$, and the stress reaches its peak at $338.6 s$, so the sliding displacement of coal occurs $2 s$ ahead of the peak stress point.

The data on the relative tensile displacement of 2\# specimen is shown in Figure 9 (c). As the data indicates, tensile displacement varies slightly when the specimen enters the elastic stage under load; after entering the stable development and expansion stage, the tensile displacement of the specimen appears to be clearly partitioned. $3 \#$ and $4 \#$ measuring points display a trend deviation towards the positive tensile direction; simultaneously, $1 \#$ and $5 \#$ measuring points display the same trend, but the overall displacement is much smaller than that at $3 \#$ and $4 \#$ measuring points. In addition, $2 \#$ and $6 \#$ measuring points show a trend of deviation towards negative tensile direction until the stress reaches its peak value. As can be seen from Figure 9 (d), at $3 \#$ measuring point, the tensile displacement witnesses a saltatory increase, and then a saltatory drop, indicating that the area of $3 \#$ measuring point is a sensitive area for tensile displacement monitoring. Compared with the data of $1 \#$ specimen, the area between $3 \#$ measuring point and $4 \#$ monitoring point in $2 \#$ specimen is the sensitive area of tensile displacement monitoring. It provides a basis for monitoring the precursor information of the main crack penetration in the specimen. The maximum tensile displacement amplitude of coal body occurs at 709.3s, and the stress reaches its peak at $707.1 \mathrm{~s}$, so the tensile displacement time lags behind the peak stress point by $2.2 s$. 


\section{Analysis On The Relationship Between Coal Stability And Energy Dissipation Damage}

Coal is loaded to break, accompanied by energy absorption, input and transformation. Based on the relationship between deformation distribution characteristics of global displacement field under coal loading and energy consumption transformation, the stability index of coal strength degradation is determined, and the internal relationship between load stability and energy consumption damage is analyzed to reveal the stability characteristic of coal deformation.

\subsection{Calculation method of strain energy ratio coefficient $M$}

Coal rock stability can be analyzed from the local damage units of coal rock in that they are closely related with each other. Therefore, the ratio (denoted as $M$ ) between the number of damage units (denoted as D1) and the statistical damage variable (denoted as $D$ ) is introduced. Equation (1) can be used as the indicator to assess the damage degree of coal rock stability. However, the information conveyed by single damage unit is highly limited. In this case, the relationship between deformation energy density and energy can be used to assess coal rock stability, which is more comprehensive and practical (Yuan et. al. 2019; Tang et. al. 2021; Gao et. al. 2020). Accordingly, the strain energy ratio coefficient $M$, which characterizes the stability of coal mass, is introduced. Deformation energy density is related with the energy generated by the deformation of damage units under load. Meanwhile, the stability of specimen is highly related with its overall strength. Consequently, the stability index $(M)$ can be calculated in the following way: at first, obtain the strain values at each measuring point in the analysis area of the deformation field; then calculate the mean value of the strain and set it as the strain value of this area; what's next, process every strain value measured during the loading course to calculate the deformation energy density of the whole loading process as well as the deformation energy density of certain moment; and finally set the ratio of the deformation energy density to the stress increment at this moment as the numerical solution of the stability index $M$. In this sense, $M$ denotes the amount of energy generated by the unit deformation caused by the unit stress change. The calculation method is shown as follows:

$$
\begin{aligned}
& N=\frac{D_{1}}{D} \\
& M=\frac{\int \sigma_{\mathrm{n}+1} d \varepsilon_{n+1}}{\sigma_{n+1}-\sigma_{n}}
\end{aligned}
$$

where $M$ denotes strain energy ratio coefficient $₫ \sigma_{n}$ stands for the stress at the moment $n \llbracket \varepsilon_{n+1}$ refers to the strain at the moment of $n+1$. 


\subsection{The analysis of coal rock stability and deformation damage}

Figure 9 shows the strain energy density curves of two types of specimens (namely, stable slip type and instantaneous instability type) during the whole loading process. The strain energy density curve of $1 \#$ specimen is shown in Figure 10 (a). As can be seen, the strain energy density displays a firstly-rise-thendecline trend in the process of loading, which is positively correlated with the stress curve. When the stress reaches its peak value, the strain energy also reaches its maximum (to be exact, $0.031 \mathrm{MJ} / \mathrm{m}^{3}$ ). And then with the penetration of main crack, the strain energy density declines correspondingly. The input energy curve of the loaded coal has always shown an increasing trend. When the specimen enters the crack propagation stage, the slope of the input energy growth curve decreases, and the dissipation energy displays a decreasing trend. When the cracks run through the coal under loading and the stress decreases, the loss energy shows an obviously increasing trend. During the early period of loading, the strain energy density increases slowly; but when the specimen enters the crack propagation stage, the strain energy density increases drastically. After the penetration of main crack, the strain energy density witnesses a declining trend and the overall decline amplitude is $22.6 \%$ of the maximum strain energy. In the late peak period, with the expansion of the internal cracks in the coal body and the deformation of the global displacement field, the strain energy density appears to drop sharply. The strain energy density curve of 2\# specimen is shown in Figure 10 (b). As can be seen, the strain energy density also displays a firstly-rise-then-decline trend in the process of loading. Due to the instantaneous slip, there is virtually no post-peak stage in the loading process. And accordingly there is no post-peak phase for the strain energy density. The input energy curve of the loaded coal shows an overall growth trend. As the specimen enters the fracture propagation stage, the slope of the input energy and the dissipation energy curves displays an increasing trend at the same time. When the main fracture of coal runs through, the stress decreases, the overall growth rate of input energy decreases as well, but the loss energy increases significantly. In the early period of loading, the strain energy density shows no obvious fluctuation. After entering the Fracture unstable expansion stage, it rises at a dip angle of approximately $45^{\circ}$ till the penetration of main crack in the specimen and reaches its maximum value of $0.038 \mathrm{MJ} / \mathrm{m}^{3}$. With the occurrence of tensile displacement and slip displacement, the strain energy density decreased to $57.9 \%$ of the maximum strain energy density. Compared with the strain energy density curve of $1 \#$ specimen, the strain energy density of $2 \#$ specimen is of a smaller order. This is related to the tensile and slip displacement of the specimen in the early loading period. As a result, the overall strain energy density of $2 \#$ specimen is low. When the main crack is formed, dynamic instantaneous slip occurs, and the strain energy is released instantly. The evolution trend of strain energy density is positively correlated with stress, but the relationship between strain energy density and coal and rock damage is not clear. Therefore, with the help of coal rock stability index $\mathrm{M}$, data are extracted to capture the relationship between coal rock stability and the whole loading process.

Figure 11 shows the stability index of specimens of different types. To be exact, Figure 11 (a) displays the relationship between the strain energy ratio coefficient $M$ and damage increment during the whole 
loading process in the case of $1 \#$ specimen. In the early period of loading, the strain energy ratio coefficient index witnesses a rise at a dip angle of $4^{\circ}$. When the specimen enters the fracture propagation stage, the dip angle rises to $78^{\circ}$. The angle deflection is $1850 \%$. while the initial angle of cumulative damage increment is $17^{\circ}$. And until the coal loading entered the crack propagation stage, the slope of the straight line segment is $70^{\circ}$, and the angle deflection is $311.7 \%$. Through the analysis of the $M$ increment data obtained in the loading process of $1 \#$ specimen, it can be known that when the main crack penetration occurs, the strain energy ratio coefficient index increment is $63 \%$ of the overall increment. Therefore, the stability characteristics of $1 \#$ specimen can be defined from two aspects: (1) the change of dip angle at which the strain energy ratio coefficient of specimens; (2) the amplitude of strain energy ratio coefficient increment. Figure 11 (b) displays the relationship between the strain energy ratio coefficient $\mathrm{M}$ and damage increment during the whole loading process in the case of $2 \#$ specimen. During the early period of loading, the strain energy ratio coefficient $M$ shows no obvious fluctuation. When the specimen enters the elastic stage, the stability index $M$ displays a rise at a dip angle of $13^{\circ}$. When the specimen enters the fracture expansion stage, the strain energy ratio coefficient $M$ rises at a dip angle of $74^{\circ}$ until the stability index reaches its maximum value and the main crack penetration occurs, with the angular deflection being $469.2 \%$. The initial angle of cumulative damage increment remains $15^{\circ}$ until the coal body is loaded into the crack propagation stage. The slope of the straight line segment is $74^{\circ}$, and the angle deflection is $393.3 \%$. Due to the instantaneous instability of the brittle specimen, there is no obvious post-peak stage, which results in the overall increasing trend of the strain energy ratio coefficient. In addition, compared with the coal strain energy ratio corresponding to the fracture area, the fracture area of the stable slip type coal is longer than the instantaneous slip duration. Therefore, by comparing the change trend of strain energy ratio coefficients of two different coal bodies, it can be seen that the deflection angle of tangent slope of strain energy density ratio increase is smaller, and the deflection angle of tangent of cumulative damage increment is larger, indicating that the instantaneous instability trend of coal body is more obvious. Its essence is closely related to the sustained characteristics of coal under load. The damage accumulation of stable equal amplitude contributes to the stable failure of coal, and the damage accumulation of interval equal amplitude has an important influence on the instantaneous instability development of coal.

Combined with the evolution law of energy consumption of the two types of coal damage, the ratio relationship between macroscopic pulling-slip and energy consumption damage is obtained as shown in Figure 12. The cumulative energy consumption damage of the stable slip type coal accounts for $63.72 \%$ of the total damage increment, and the cumulative energy consumption duration is $545.18 \mathrm{~s}$, of which the cumulative damage in the elastic stage is $3.59 \%$, the cumulative damage in the compaction stage is $11.1 \%$, the damage accumulation is $35.89 \%$ at the stable crack propagation stage, and $13.14 \%$ at the unsteady crack propagation stage. The energy consumption damage of the instantaneous instability coal body accounts for $96.35 \%$ of the total damage increment, and the cumulative energy consumption time is $514.58 \mathrm{~s}$, of which the cumulative damage in the elastic phase is $0.491 \%$, the damage accumulation in the compaction stage is $9.54 \%$, and the damage accumulation is $2.093 \%$ in the stable growth stage of the crack, and $84.226 \%$ in the unsteady growth stage of the crack. By analyzing the energy consumption 
damage characteristics of two different types of coal, it can be clearly found that the accumulation of energy consumption damage that causes the macro-fracture of coal mainly occurs in the fracture expansion stage. Among them, the main energy consumption damage accumulation stage of the stableslip coal is the fracture stable expansion stage, and the main energy consumption damage accumulation stage of the instantaneous instability coal is the fracture unsteady expansion stage. It is shown that the fracture expansion stage is the main stage of coal damage accumulation, and the proportion of damage accumulation determines the type of coal failure instability.

\section{Conclusions}

Through the experimental study on localization loading of coal energy dissipation damage deformation, the localization distribution characteristic of coal under load and the deformation law of global displacement field are analyzed, and the strain energy ratio coefficient $\mathrm{M}$ based on energy consumption relationship is proposed. The conclusions are as follows:

(1) In the early stage of coal loading, there is an evolution of internal balance degree from disorder to order, and the working time of stable sliding type in the whole process is $60 \%$ that of instantaneous instability type. Before the loading peak, the characteristic of shear strain localization zone evolves from "local divergence" to "local concentration", which shows the evolution trend of deformation localization zone from divergence to concentration.

(2) As can be seen, there are positive and negative stretching and positive and negative sliding in the global deformation displacement field of coal loading. The monitoring point $2 \#$ shows negative sliding, and the monitoring point $6 \#$ shows negative stretching, indicating that the deformation of the global displacement field of coal has regional consistency, and the main fracture expansion provides certain direction guidance.

(3) There is a difference between the peak stress reduction time of coal body and the maximum displacement deformation time, indicating that the strength reduction of coal body is affected by the deformation accumulation of loading displacement field. The occurrence of sliding displacement and tensile displacement in the deformation displacement field also has non-synchronous characteristics. Among them, the sliding displacement of the stable sliding type specimen occurs $5.5 \mathrm{~s}$ earlier than tensile displacement, accounting for $1.25 \%$ of the loading time of coal body; the sliding displacement of the instantaneous instability type specimen occurs $1.1 \mathrm{~s}$ earlier than tensile displacement, accounting for $0.15 \%$ of the loading time of coal body.

(4) Dissipative energy of coal shows an obvious increasing trend during fracture propagation. The overall input energy density of stable sliding type is obviously larger than that of instantaneous instability type, but the strain energy density of stable slip type is smaller than that of instantaneous instability type. When the main fracture runs through, the strain energy density of stable sliding type coal decreases by $22.6 \%$, and the strain energy density of instantaneous instability type coal decreases by $57.9 \%$. 
(5) The smaller the deflection angle of tangent slope of strain energy ratio coefficient is, the larger the deflection angle of tangent slope of damage accumulation increment is, which indicates that the trend of instantaneous instability of specimens is more obvious. Its essence is closely related to the sustained characteristic of coal under load. The damage accumulation of stable equal amplitude contributes to the stable failure of coal, and the damage accumulation of interval equal amplitude has an important influence on the instantaneous instability development of coal.

(6) The fracture expansion stage is the main stage of coal damage accumulation, and the proportion of damage accumulation determines the type of coal failure instability. That is the main energy consumption damage accumulation stage of the stable slip coal is the stable crack expansion stage, while the main energy consumption damage accumulation stage of the instantaneous instability coal is the unsteady crack expansion stage.

\section{Declarations}

\section{Declaration of competing interest}

The authors declare that they have no known competing financial interests or personal relationships that could have appeared to influence the work reported in this paper.

\section{Acknowledgements}

This work was supported by the National Key R\&D Program Funding Project (2017YFC0804205), the National Natural Science Foundation of China (project number: 51774048), Fundamental Research Funds for the Central Universities (project number: FRF-TP-19-009B1). The authors wish to acknowledge these supports. At the same time, authors are very grateful for the anonymous reviewers' valuable comments.

\section{References}

Fakhimi A, Hosseini O, Theodore R (2016) Physical and numerical study of strain burst of mine pillars. Computers and Geotechnics. 2016; 74:36-44.

Wu H, Zhao J, Liang W (2020) Pattern transitions of localized deformation in high-porosity sandstones: Insights from multiscale analysis. Computers and Geotechnics. 2020; 126:103733.

Wang H, Shi R, Deng D, Jiang Y, Wang G, Gong W (2020) Characteristic of stress evolution on fault surface and coal bursts mechanism during the extraction of longwall face in Yima mining area, China. Journal of Structural Geology. 2020; 136:104071.

Pan YS. Disturbance response instability theory of rockburst in coal mine (2018) Journal of china coal society. 2018; 43(08):2091-8. 
Dou LM, Feng LF, Cai W, Wang H, He HH, Jiao B, Zhang M (2020) Seismo-acoustic precursor identification and comprehensive warning model for the catastrophic failure process of coal and rock. Journal of Mining and Safety Engineering. 2020; 37:960-8.

Dou LM, Wang SC, Gong SY, Cai W, Li XL (2020) Cloud platform of rock-burst intelligent risk assessment and multi-parameter monitoring and early warning. Journal of china coal society. 2020:1-8.

Kang HP (2020) Temporal scale analysis on coal mining and strata control technologies. Journal of Mining and Strata Control Engineering. 2020:1-23.

Tuncay D, Tulu IB, Klemetti T (2021) Investigating different methods used for approximating pillar loads in longwall coal mines. International Journal of Mining Science and Technology. 2021; 31:23-32.

Jing H, Wu J, Yin Q, Wang K (2020) Deformation and failure characteristics of anchorage structure of surrounding rock in deep roadway. International Journal of Mining Science and Technology. 2020; 30:593-604.

Maleki H (2017) Coal pillar mechanics of violent failure in U.S. Mines. International Journal of Mining Science and Technology. 2017; 27:387-92.

Yang XB, Han XX, Liu EL, Zhang ZP, Wang TJ, Zhang LH (2018) Properties of non-uniform deformation evolution of rock under uniaxial cyclic loading and unloading. Journal of China Coal Society. 2018; 43:449-456.

Yang XB, Han XX, Wang XY, Zhang ZP (2019) Displacements evolution laws of deformation localization bands of rock under constant amplitude cyclic landing. Journal of China Coal Society. 2019; 44:10411048.

Peng SJ, Ran XM, Xu J, Chen CC, Song XH, Yan FZ (2020) Experimental study on loading rate effects of sandstone deformation localization based on 3D-DIC technology. Rock and Soil Mechanics. 2020; 41:3591-603.

Zhang TJ, Jing C, Zhang L, Ji X, Pan HY (2020) Strain localization characteristics of perforation failure of perforated specimens. Journal of China Coal Society. 2020; 45(12): 4087-4094.

Qinrong K, Weizhong Z, Gun H, Dianji Z (2019) Theoretical and experimental bifurcation analysis of rock under plane strain compression. Arab J Geosci. 2019; 12.

Xing T, Zhu H, Liu G, Song Y, Ma S (2020) Global Mechanical Behavior Characterization of Uniaxially Loaded Rock Specimen Based on Its Structural Evolution. Applied Sciences. 2020; 10:7647.

Fazio NL, Leo M, Perrotti M, Lollino P (2019) Analysis of the Displacement Field of Soft Rock Samples During UCS Tests by Means of a Computer Vision Technique. Rock Mech Rock Eng. 2019; 52:3609-26. 
Lei R, Zhang Z, Ge Z, Berto F, Wang G, Zhou L (2020) Deformation localization and cracking processes of sandstone containing two flaws of different geometric arrangements. Fatigue Fract Eng M. 2020; 43:1959-77.

Wang G, Liu Y, Xu J (2021) Stress Localization in Brittle Rock-Like Samples of Particle-Filled Joints under Direct Shear Loading. Ksce J Civ Eng. 2021; 25:345-55.

Li Y, Zhang D, Fang Q, Yu Q, Xia L (2014) A physical and numerical investigation of the failure mechanism of weak rocks surrounding tunnels. Comput Geotech. 2014; 61:292-307.

Zhou Z, Chen L, Zhao Y, Zhao T, Cai X, Du X (2017) Experimental and Numerical Investigation on the Bearing and Failure Mechanism of Multiple Pillars Under Overburden. Rock Mech Rock Eng. 2017; 50(4):995-1010.

Li G, Cao S, Luo F, Li Y, Wei Y (2018) Research on mining-induced deformation and stress, insights from physical modeling and theoretical analysis. Arab J Geosci. 2018; 11(5).

Sun Q, Cai C, Zhang S, Tian S, Li B, Xia Y, Sun Q (2019) Study of localized deformation in geopolymer cemented coal gangue-fly ash backfill based on the digital speckle correlation method. Constr Build Mater. 2019; 215:321-31.

Xie Z, Zhang N, Meng F, Han C, An Y, Zhu R (2019) Deformation Field Evolution and Failure Mechanisms of Coal-Rock Combination Based on the Digital Speckle Correlation Method. Energies. 2019; 12(13):2511.

Yang L, Ding C, Yang R, Lei Z, Wang J (2018) Full Field Strain Analysis of Blasting Under High Stress Condition Based on Digital Image Correlation Method. Shock Vib. 2018; 2018:1-7.

Cao R, Lin H, Cao P (2018) Strength and failure characteristics of brittle jointed rock-like specimens under uniaxial compression: Digital speckle technology and a particle mechanics approach. International Journal of Mining Science and Technology .2018; 28:669-77.

Song YM, Jiang YD, Ma SP, Yang XB, Zhao TB (2012) Evolution of deformation fields and energy in whole process of rock failure. Rock and Soil Mechanics. 2012; 33:1352-6.

Yuan C, Yuan Z, Wang Y, Li C (2019) Analysis of the diffusion process of mining overburden separation strata based on the digital speckle correlation coefficient field. Int J Rock Mech Min. 2019; 119:13-21.

Tang JP, Hao N, Pan YS, Sun SJ (2021) Experimental study on precursor characteristics of coal and gas outburst based on acoustic emission energy analysis. Chinese Journal of Rock Mechanics and Engineering. 2021; 40:31-42.

Gao L, Gao F, Zhang Z, Xing Y (2020) Research on the energy evolution characteristics and the failure intensity of rocks. International Journal of Mining Science and Technology 2020; 30:705-13. 
Figures

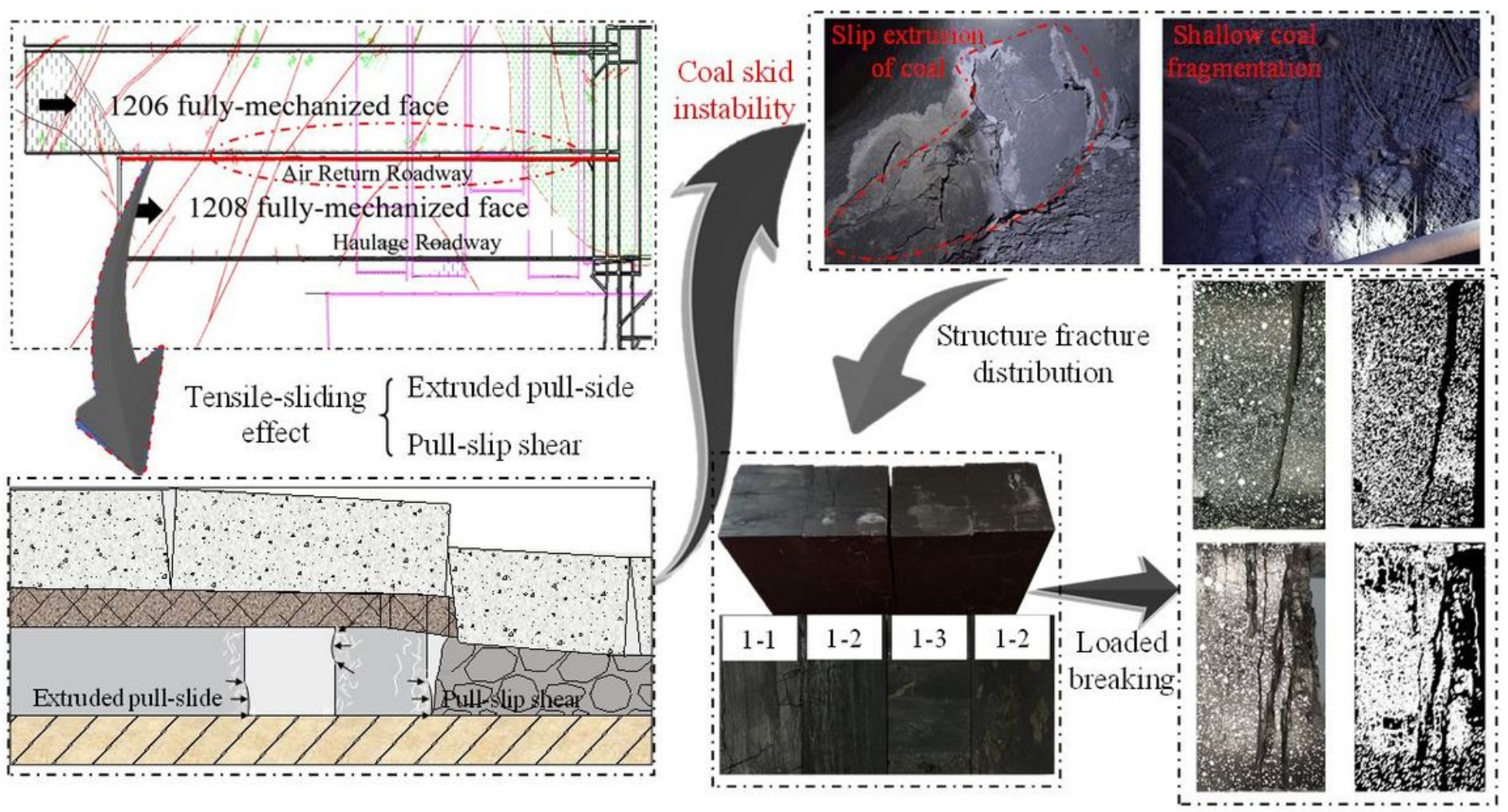

Figure 1

Engineering structure model diagram 


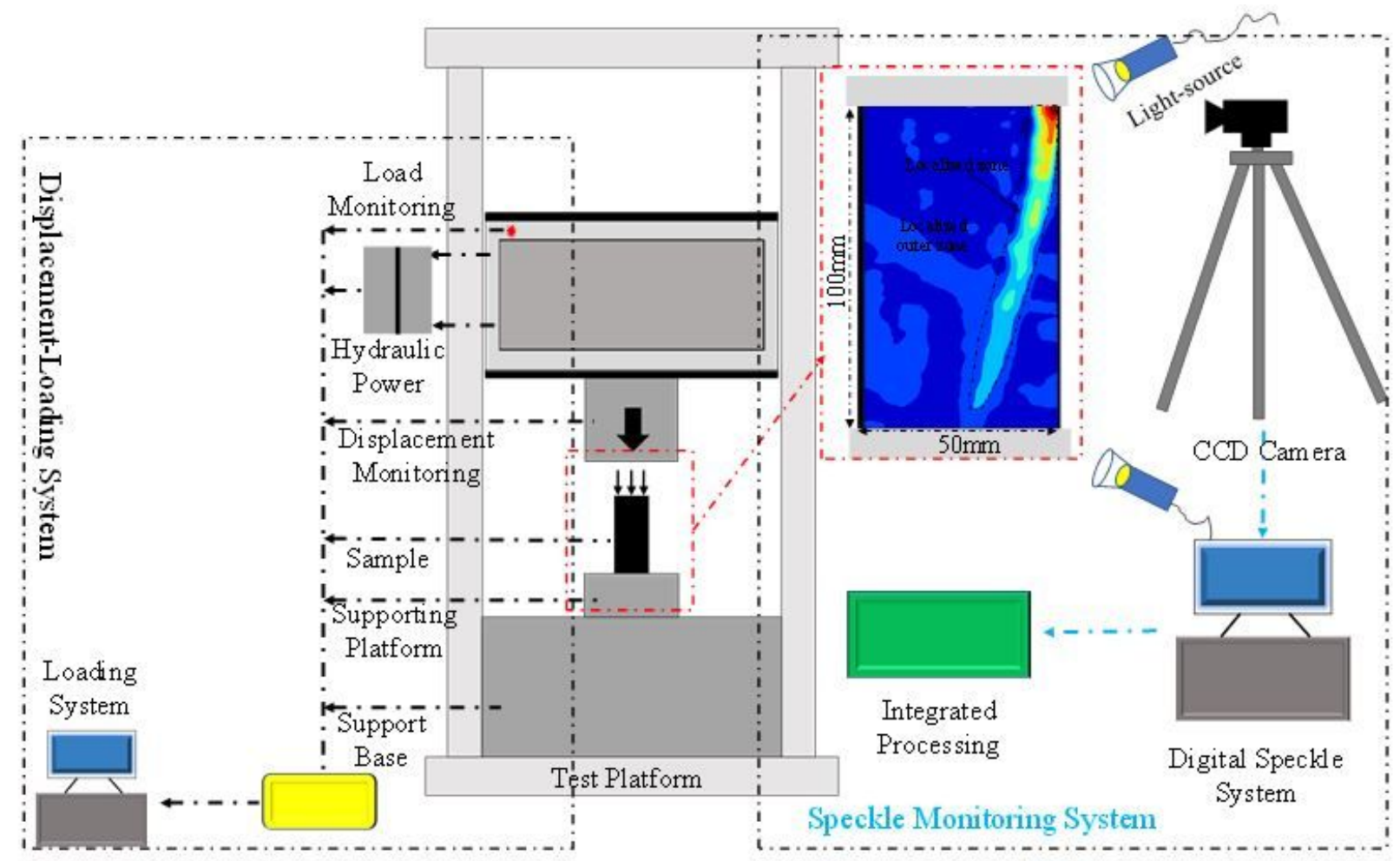

(a)

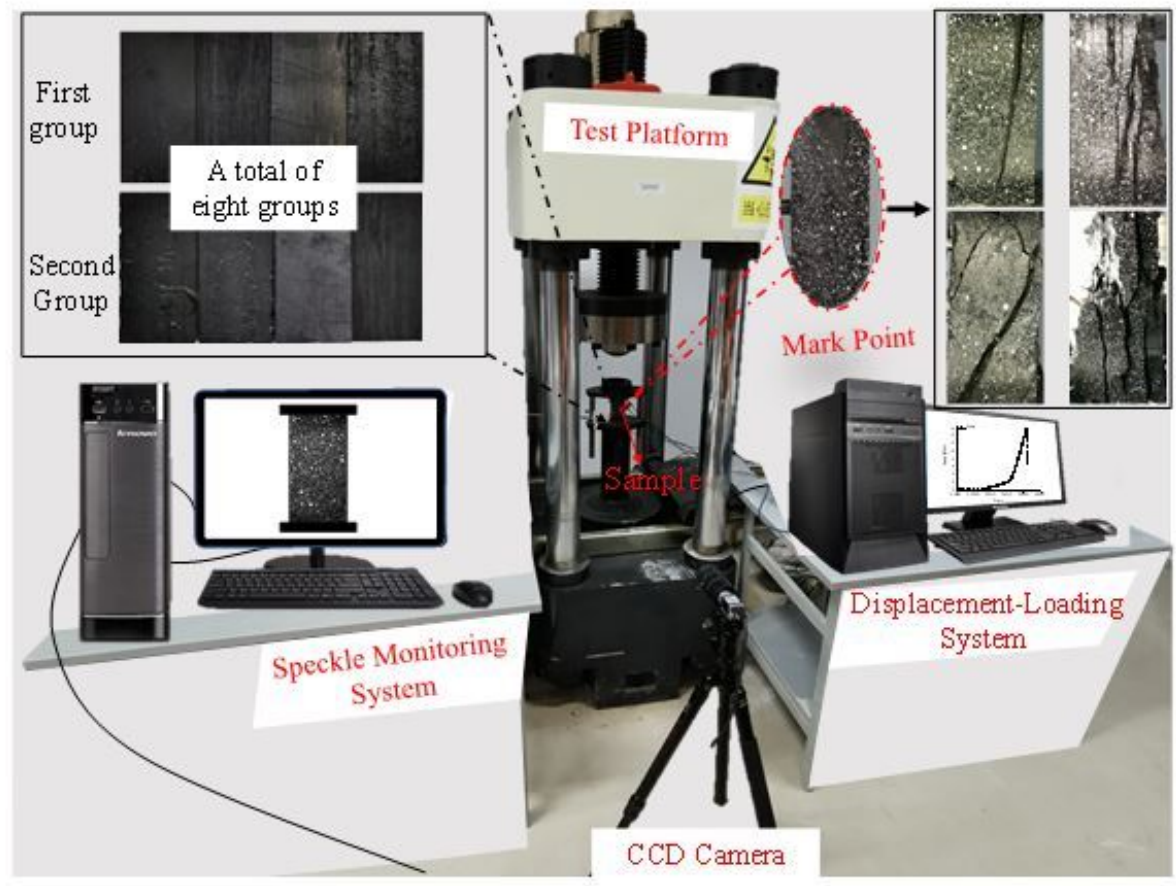

(b)

\section{Figure 2}

Experimental device system and device pictures; (a) Model diagram (b) Physical map. 

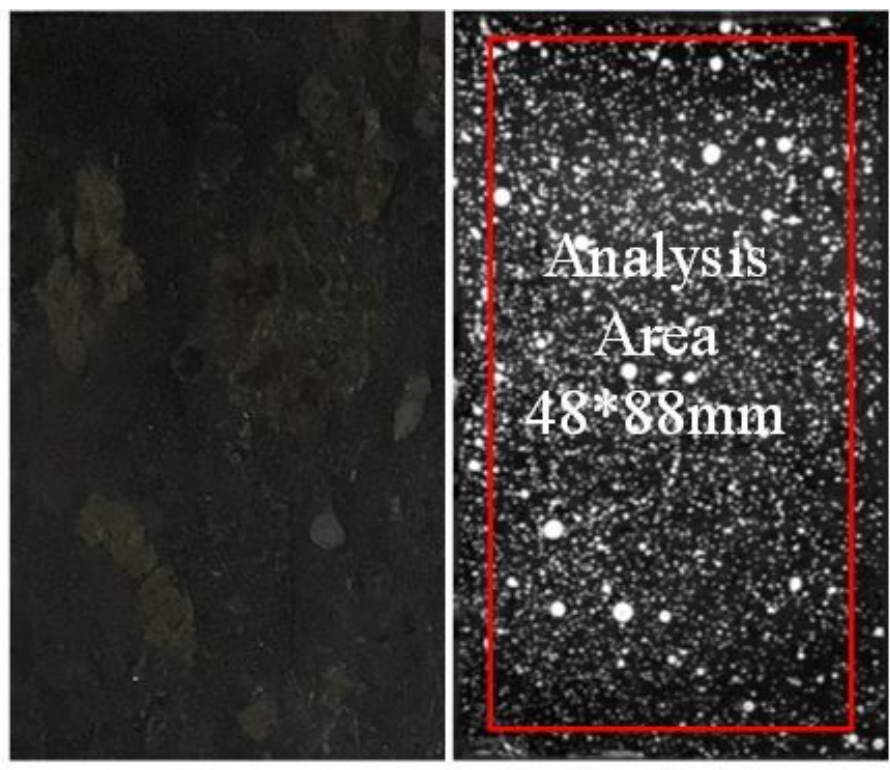

(a)

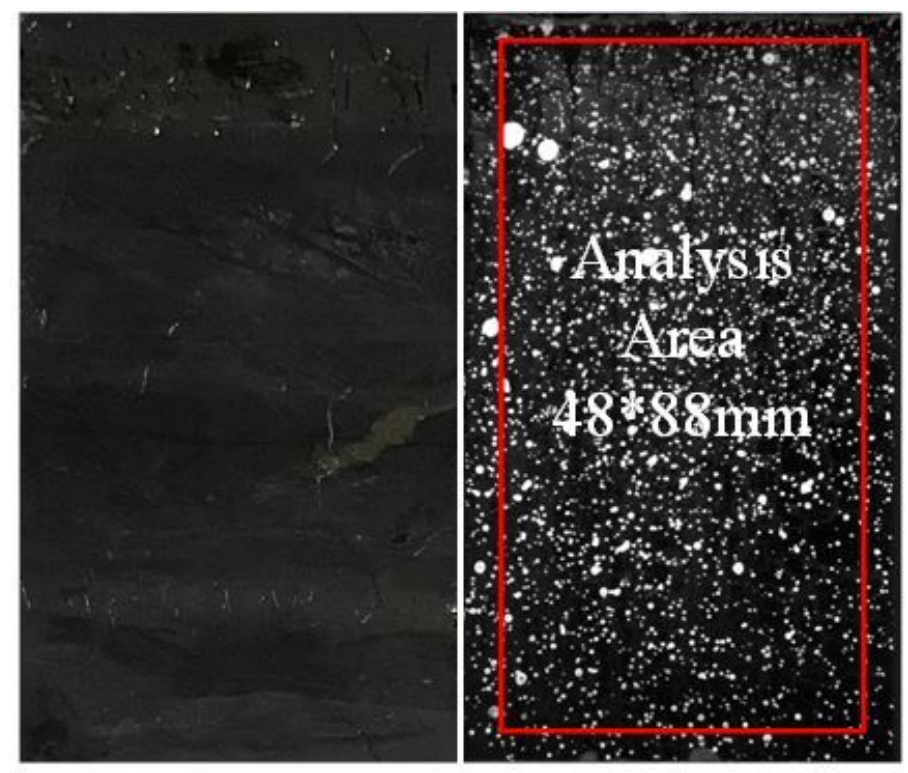

(b)

\section{Figure 3}

The two specimens and their speckle image analysis areas; (a) $1 \#$ specimen of stable slip (b) 2\# specimen of instantaneous instability 


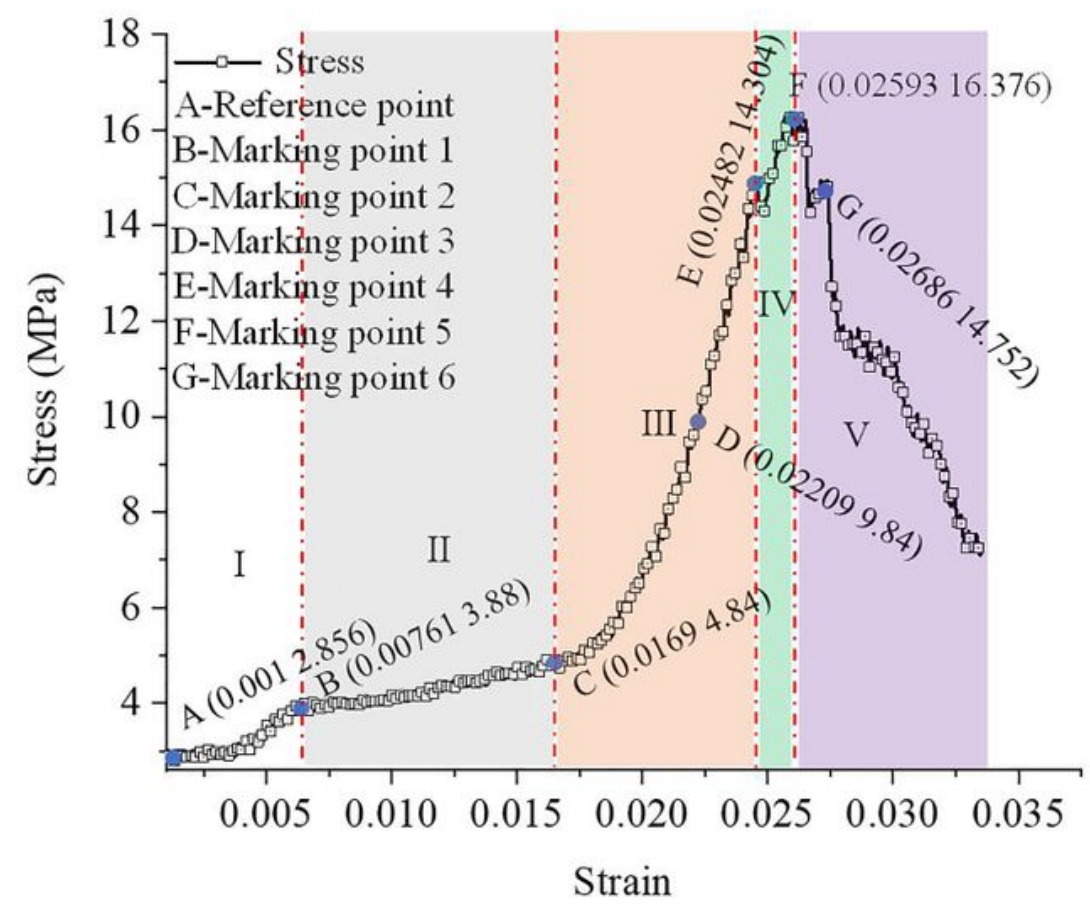

(a)

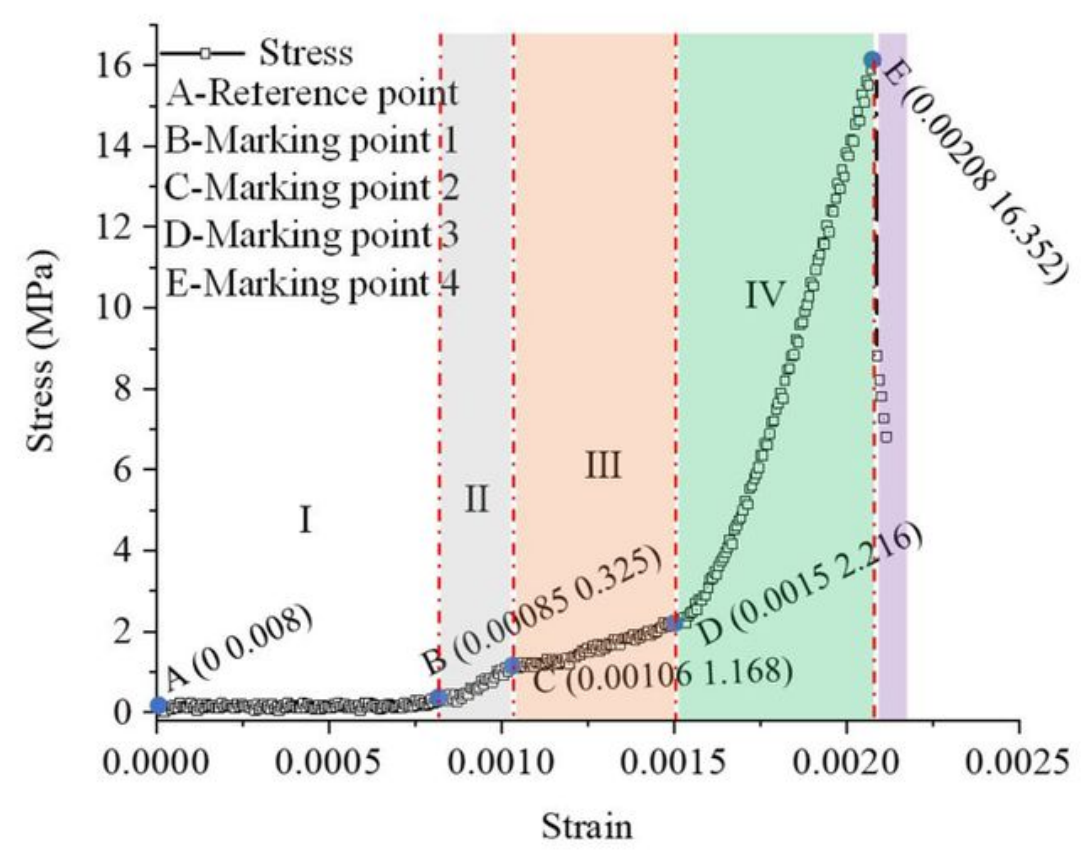

(b)

\section{Figure 4}

The stress-strain curve of the whole loading process; (a) 1\# specimen of stable slip (b) 2\# specimen of instantaneous instability. 


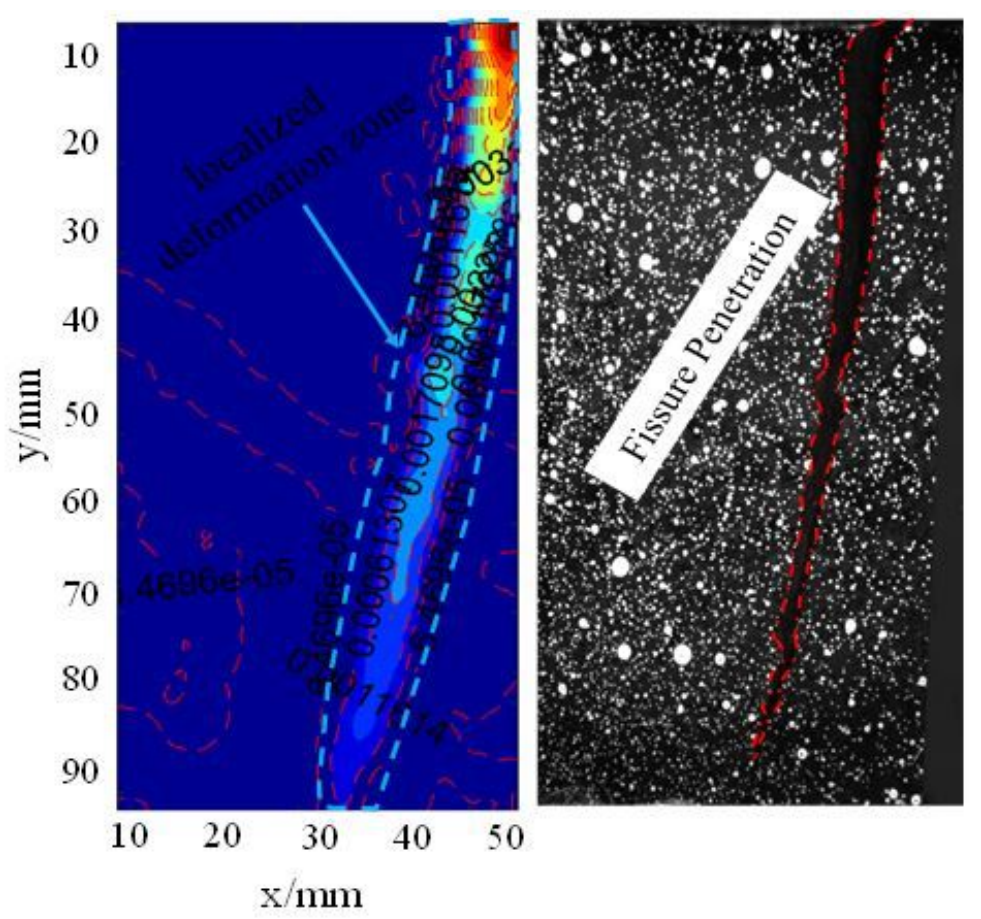

(a)

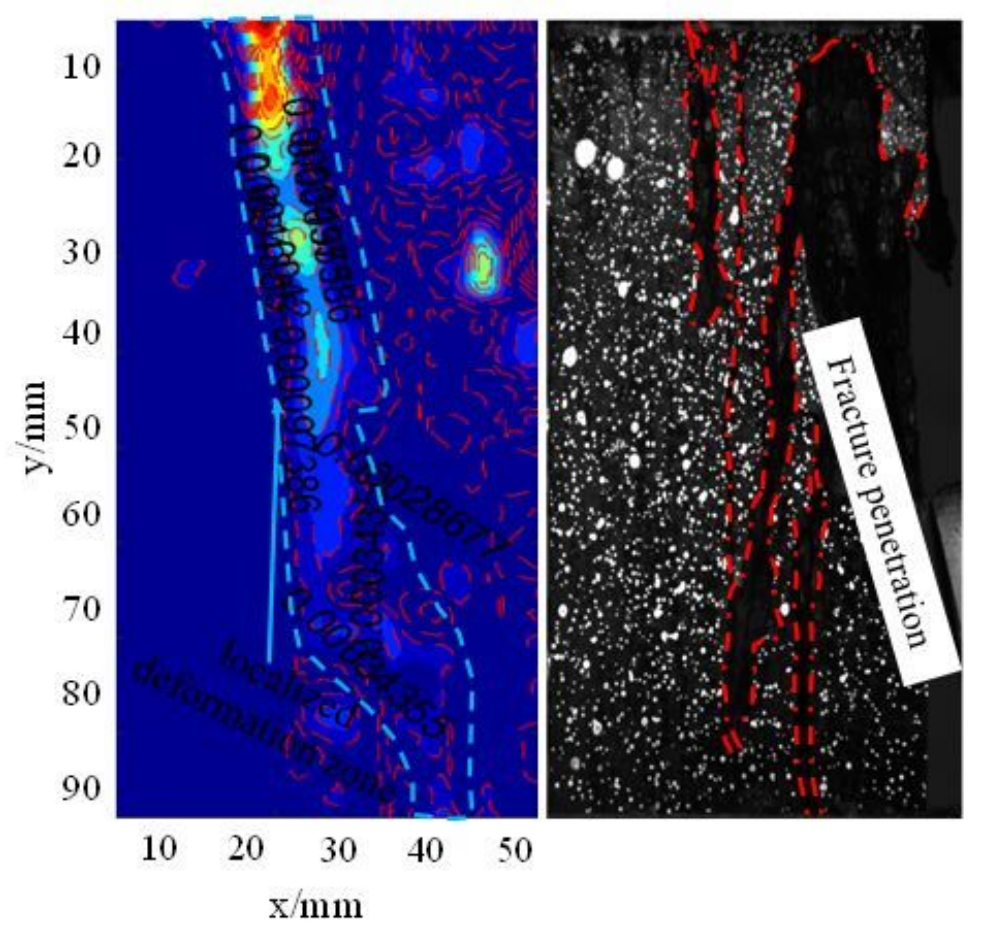

(b)

\section{Figure 5}

Failure modes and maximum shear strain diagram; (1) 1\# specimen of stable slip (b) 2\# specimen of instantaneous instability. 


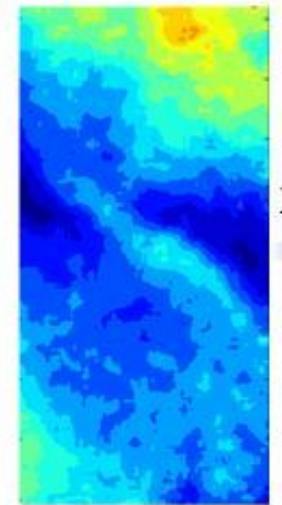

$5 s$

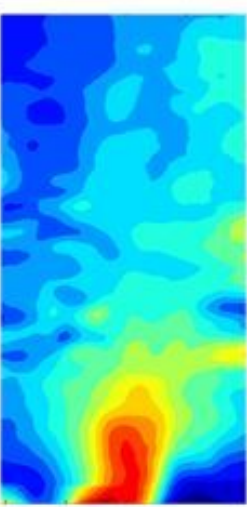

$323.75 \mathrm{~s}$

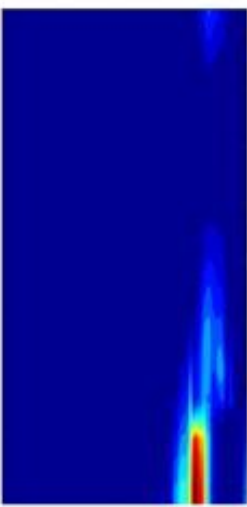

$339 \mathrm{~s}$

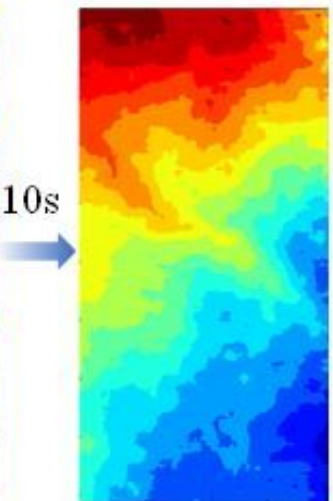

$15 \mathrm{~s}$
$5 \mathrm{~s}$

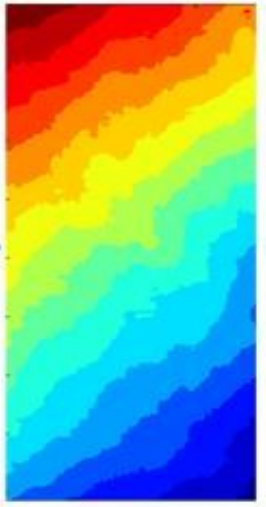

$20 \mathrm{~s}$
$60 \mathrm{~s}$

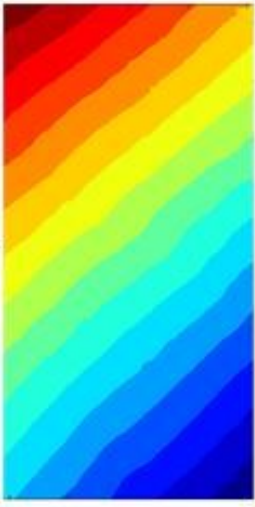

80 s

(a)

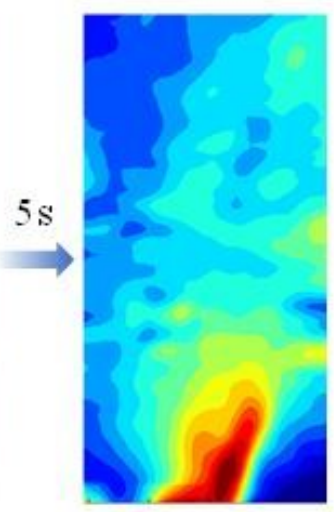

$328.75 \mathrm{~s}$

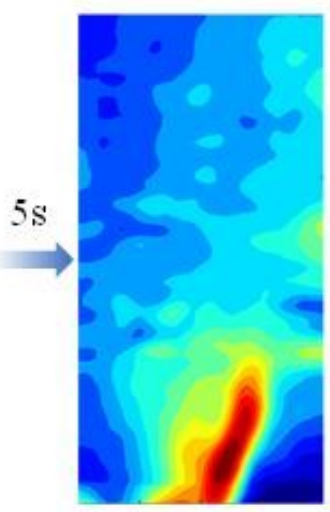

$333.75 \mathrm{~s}$

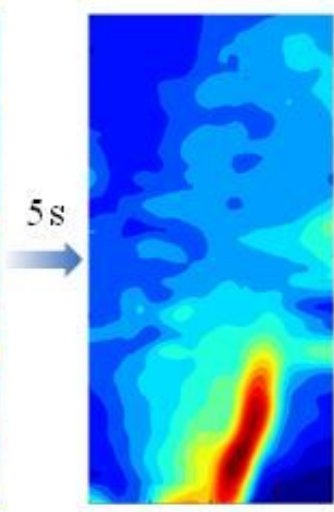

$338.75 \mathrm{~s}$

(b)

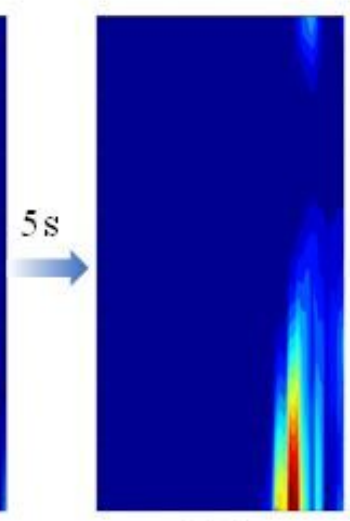

344 s

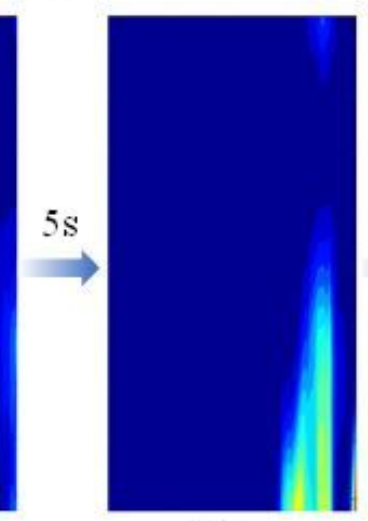

$349 \mathrm{~s}$

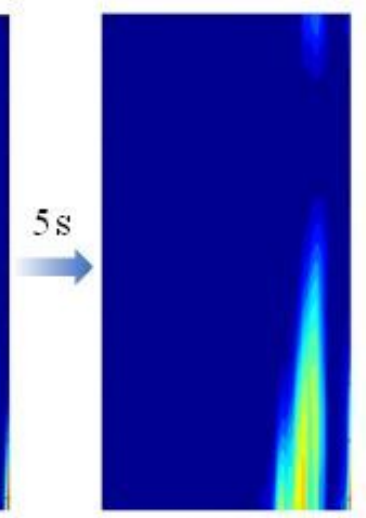

$354 \mathrm{~s}$

(c)

\section{Figure 6}

The speckle calculation nephogram of 1\# specimen (stable slip type); (a) The evolution of balance degree (b) The shear strain localization band (c) Post-peak localization band. 


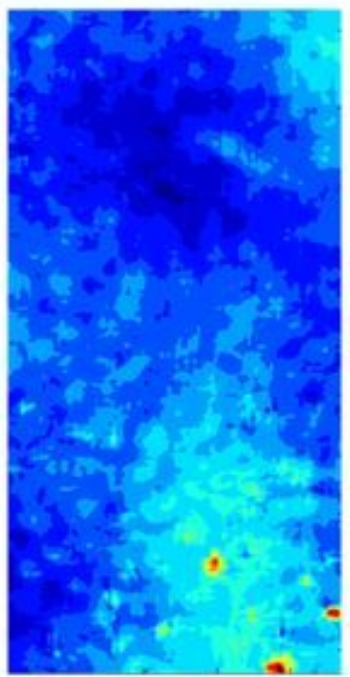

$7.5 \mathrm{~s}$

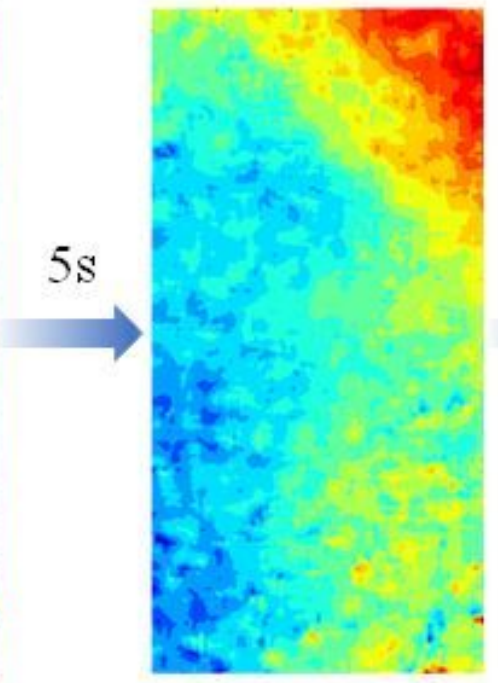

$12.5 \mathrm{~s}$

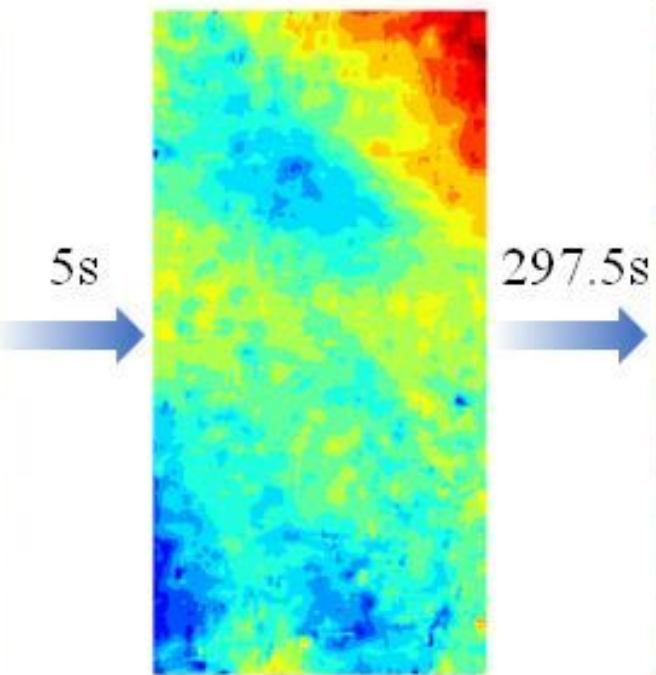

$17.5 \mathrm{~s}$

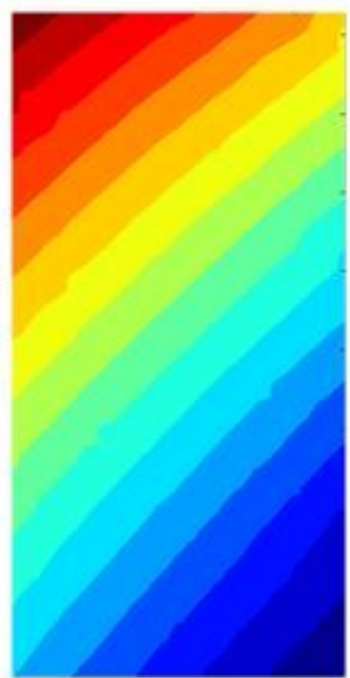

$315 \mathrm{~s}$

(a)

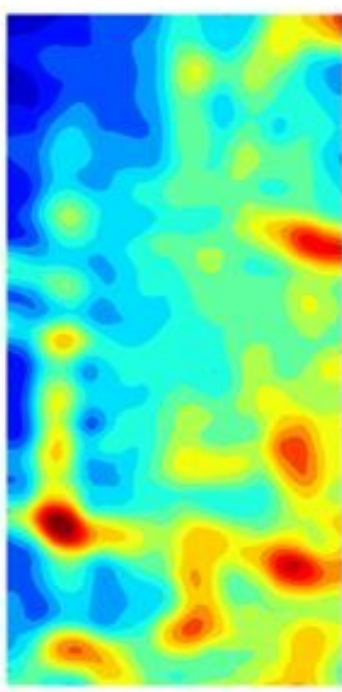

$692.25 \mathrm{~s}$

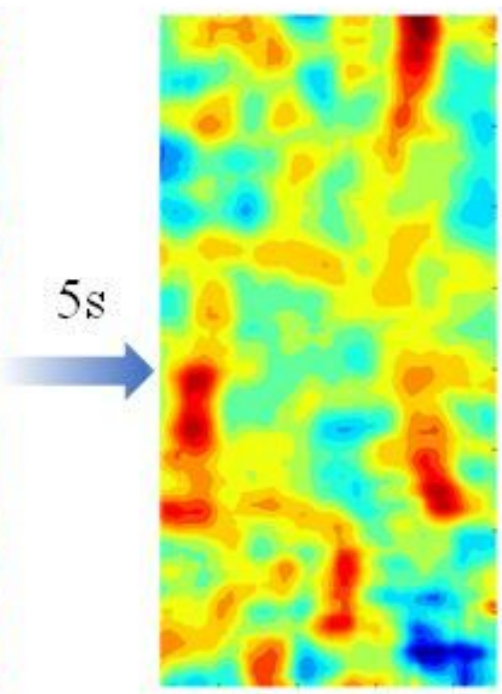

$697.25 \mathrm{~s}$
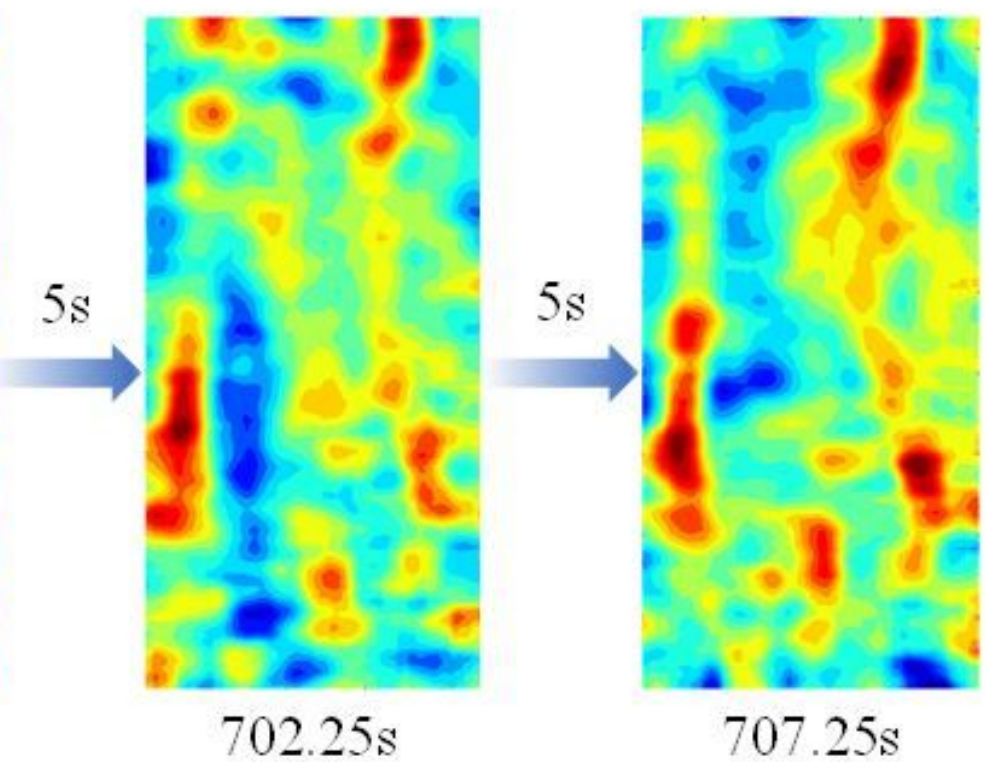

(b)

\section{Figure 7}

The speckle calculation nephogram of 2\# specimen (instantaneous instability type); (a) The evolution of balance degree (b) The shear strain localization band. 


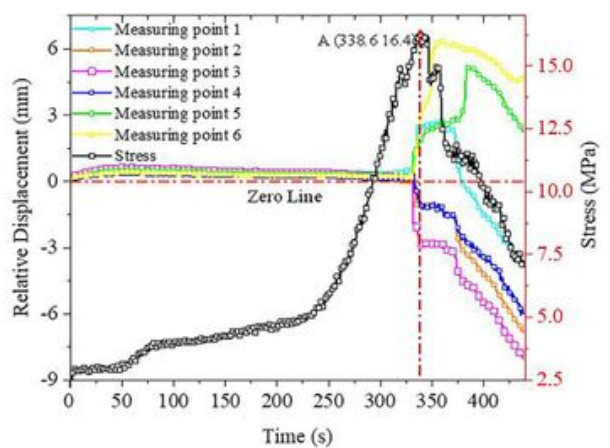

(a)

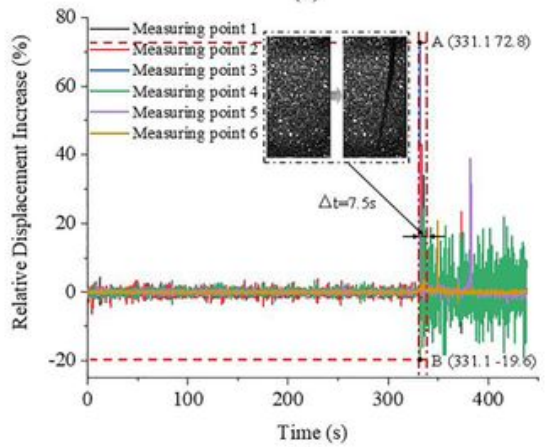

(b)

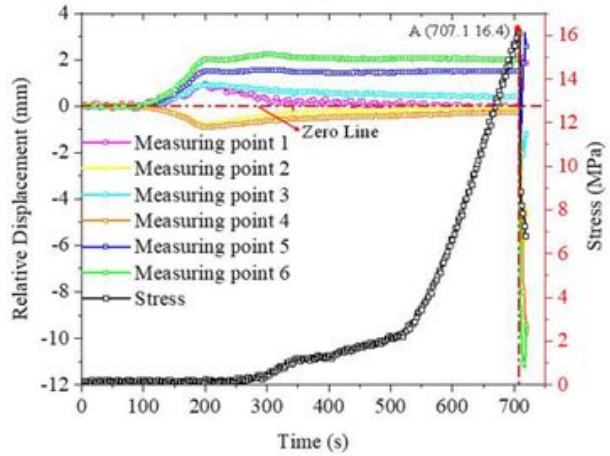

(c)

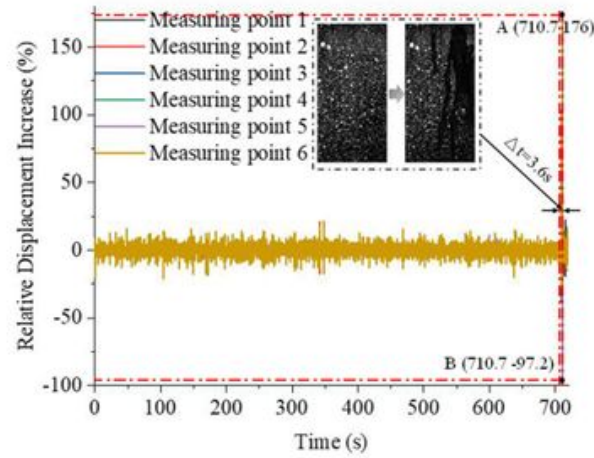

(d)

\section{Figure 8}

The characteristics of displacement distribution; (a) The relative displacement of $1 \#$ specimen (b) The relative displacement amplitude of $1 \#$ specimen (c) The relative displacement of $2 \#$ specimen (d) The relative displacement amplitude of $2 \#$ specimen. 


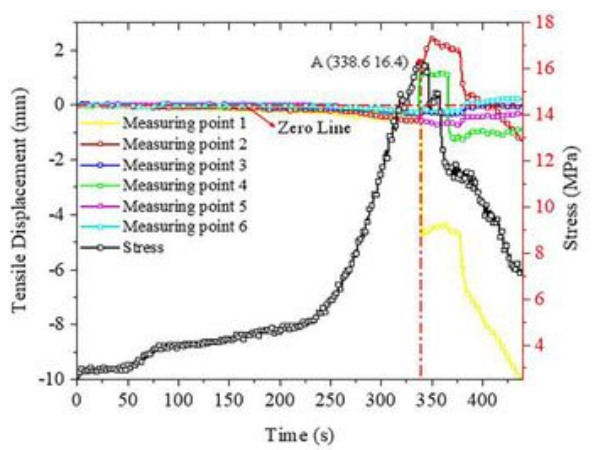

(a)

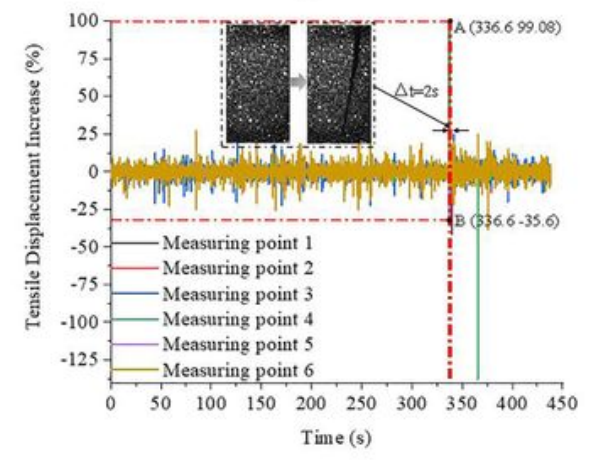

(b)

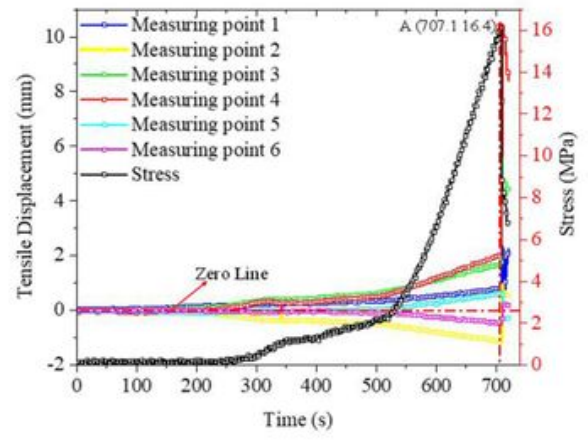

(c)

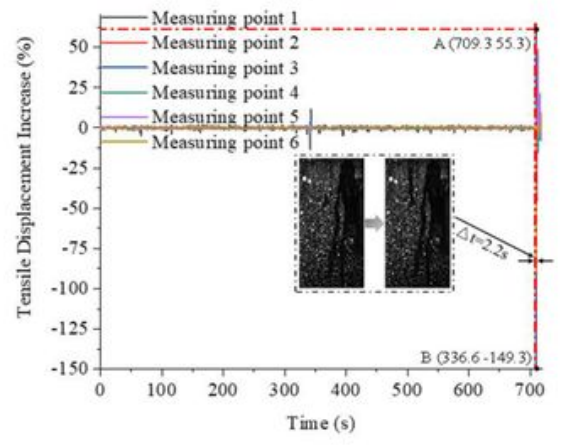

(d)

\section{Figure 9}

The characteristic of tensile distribution; (a) The relative tensile displacement of 1 \# specimen (b) The relative tensile displacement amplitude of $1 \#$ specimen (c) The relative tensile displacement of $2 \#$ specimen (d) The relative tensile displacement amplitude of $2 \#$ specimen. 


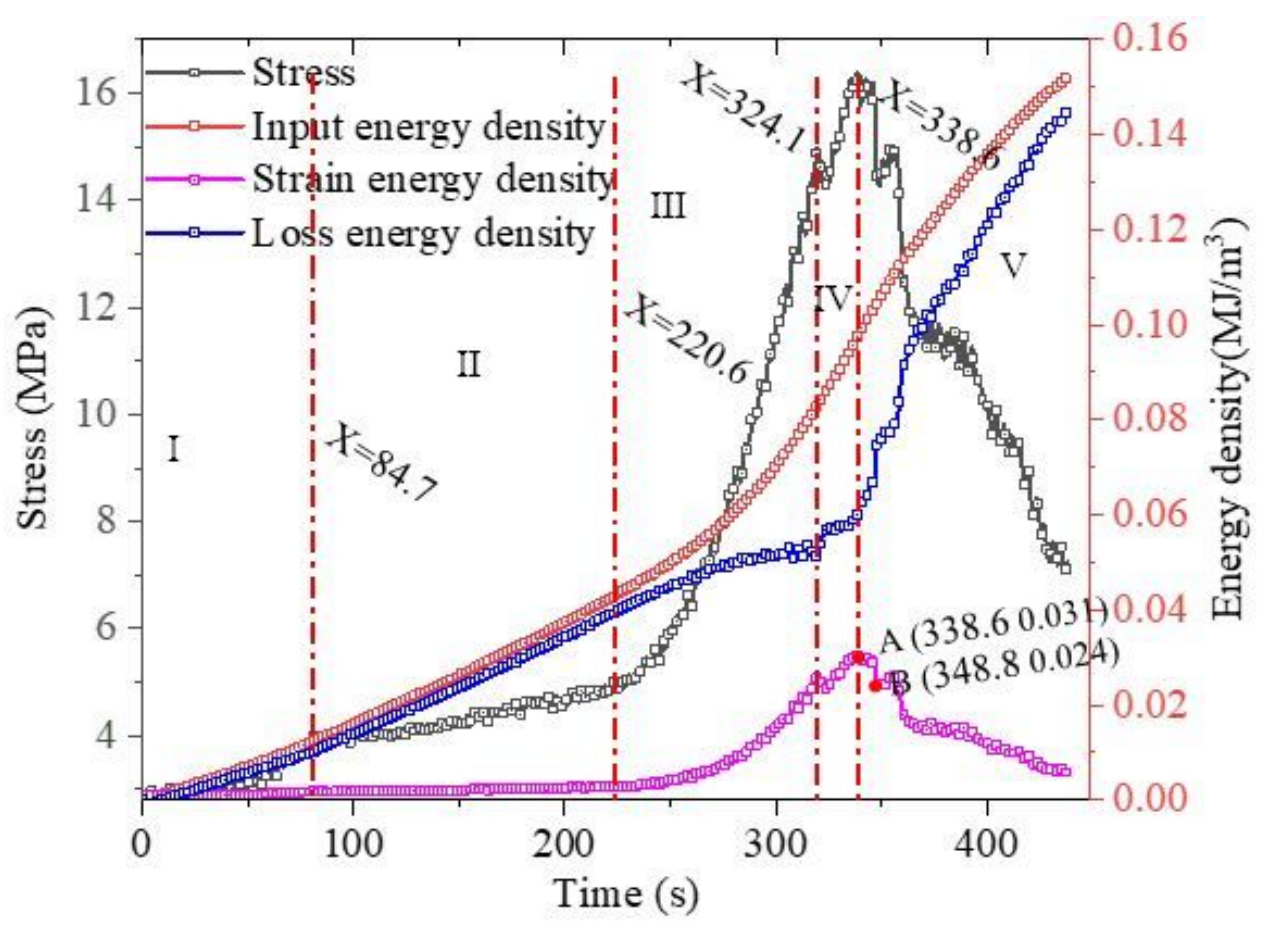

(a)

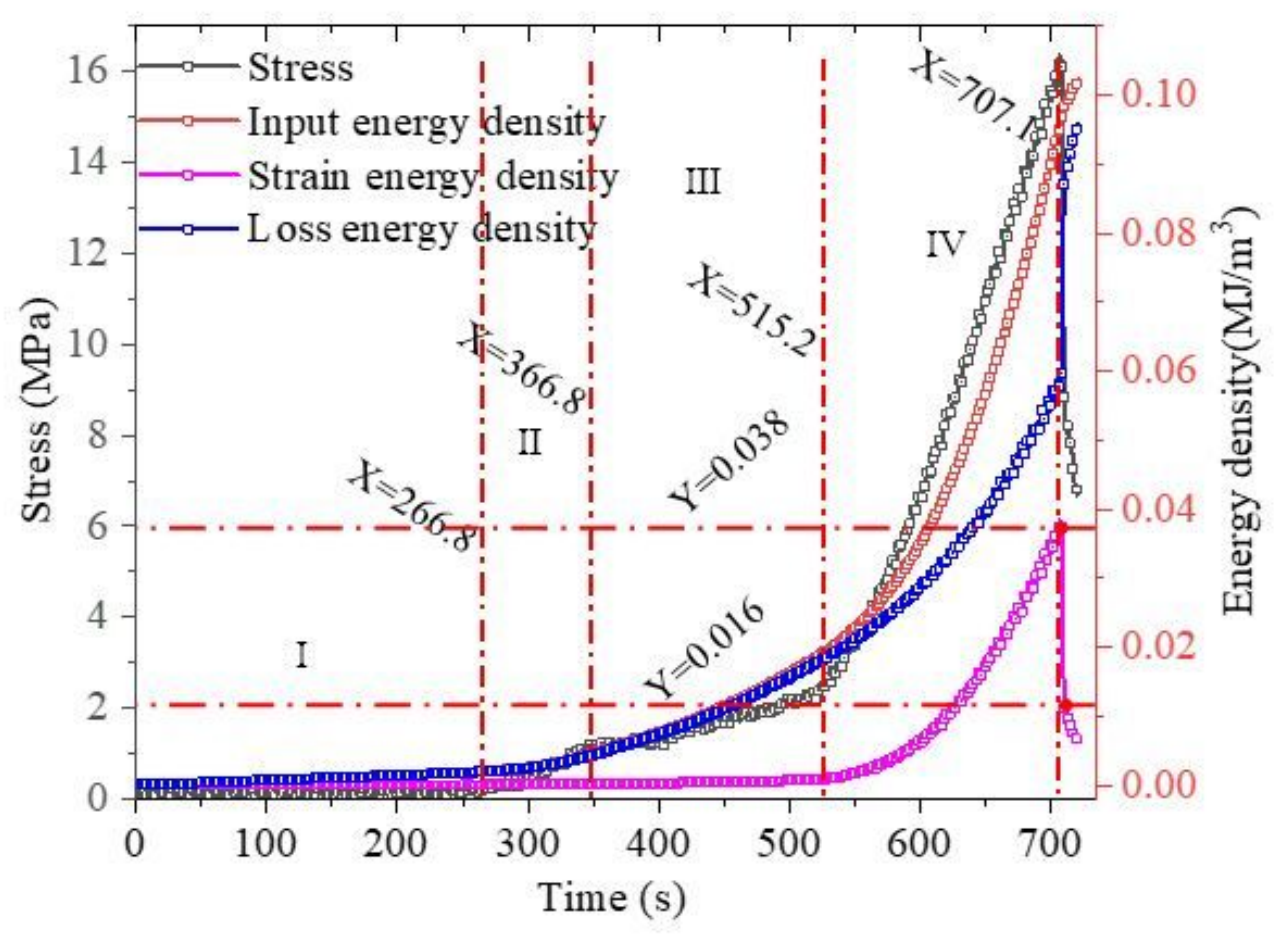

(b)

\section{Figure 10}

Loading energy curves of different specimens; (a) Specimen of stable slip type (b) Specimen of instantaneous instability. 


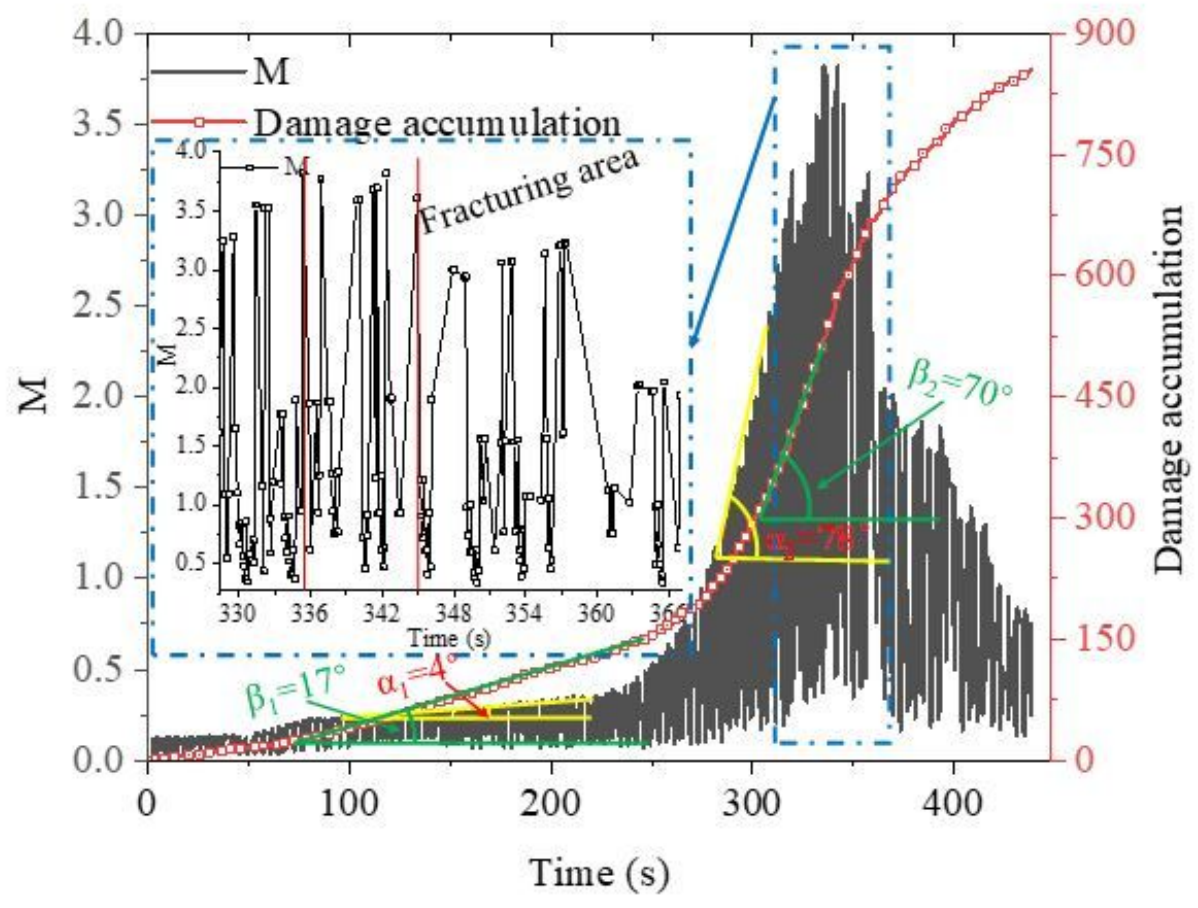

(a)

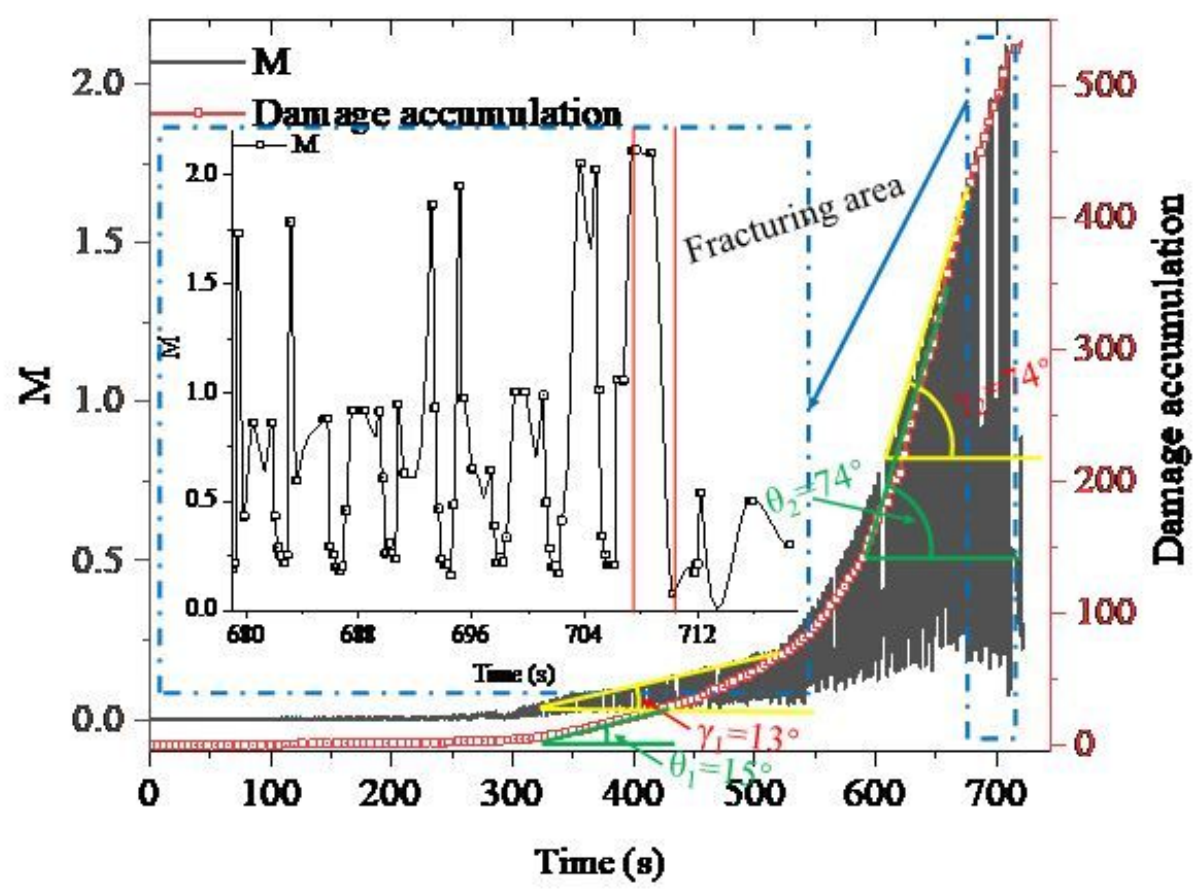

(b)

Figure 11

Damage energy curves of different types of coal; (a) Specimen of stable slip type (b) Specimen of instantaneous instability. 


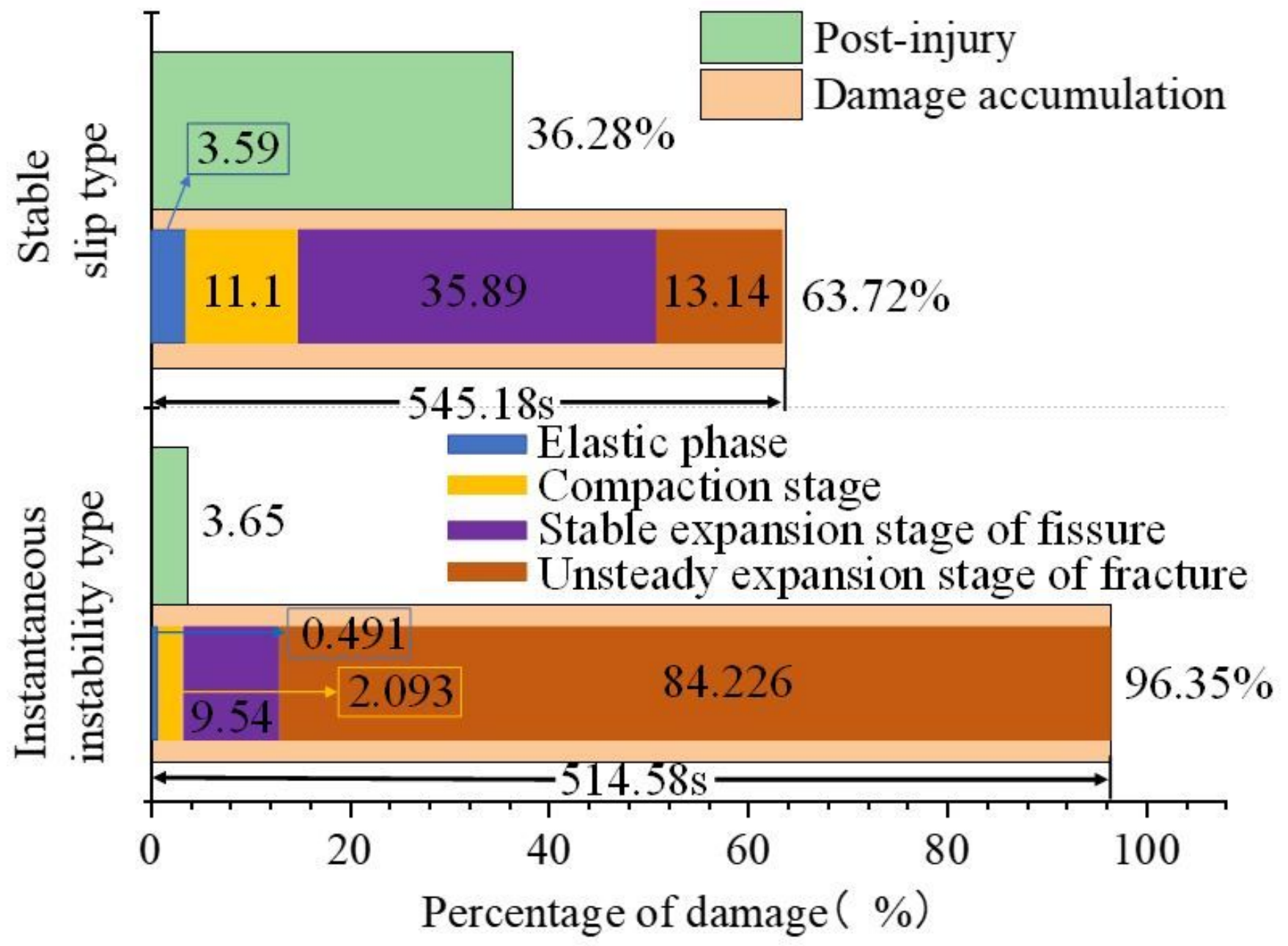

Figure 12

Diagram of the proportion of energy consumption damage 